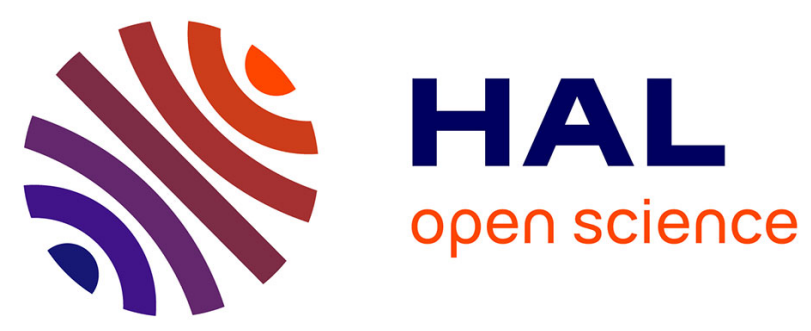

\title{
Tracing interactions between natural argillites and hyper-alkaline fluids from engineered cement paste and concrete: Chemical and isotopic monitoring of a 15-years old deep-disposal analogue
} Isabelle Techer, Daniele Bartier, Philippe Boulvais, E Tinseau, K Suchorski, Justo Cabrera, Alexandre Dauzères

\section{To cite this version:}

Isabelle Techer, Daniele Bartier, Philippe Boulvais, E Tinseau, K Suchorski, et al.. Tracing interactions between natural argillites and hyper-alkaline fluids from engineered cement paste and concrete: Chemical and isotopic monitoring of a 15-years old deep-disposal analogue. Applied Geochemistry, 2012, 27 (7), pp.1384-1402. 10.1016/j.apgeochem.2011.08.013 . insu-01544216

\author{
HAL Id: insu-01544216 \\ https://hal-insu.archives-ouvertes.fr/insu-01544216
}

Submitted on 11 Jul 2017

HAL is a multi-disciplinary open access archive for the deposit and dissemination of scientific research documents, whether they are published or not. The documents may come from teaching and research institutions in France or abroad, or from public or private research centers.
L'archive ouverte pluridisciplinaire HAL, est destinée au dépôt et à la diffusion de documents scientifiques de niveau recherche, publiés ou non, émanant des établissements d'enseignement et de recherche français ou étrangers, des laboratoires publics ou privés.

\section{(ㅇ)(1) $\$$}

Distributed under a Creative Commons Attribution - NonCommercial - NoDerivatives 44.0 


\title{
Tracing interactions between natural argillites and hyper-alkaline fluids from engineered cement paste and concrete: Chemical and isotopic monitoring of a 15-years old deep-disposal analogue
}

\author{
I. Techer ${ }^{\mathrm{a}, *}$, D. Bartier ${ }^{\mathrm{b}}$, Ph. Boulvais ${ }^{\mathrm{c}}$, E. Tinseau ${ }^{\mathrm{d}}$, K. Suchorski $^{\mathrm{c}}$, J. Cabrera $^{\mathrm{d}}$, A. Dauzères $^{\mathrm{d}}$ \\ ${ }^{2}$ GIS/CEREGE, CNRS-UMR CNRS 6635, Université de Nîmes et d'Aix-Marseille, Parc Scientifique Georges Besse, 150 rue Georges Besse, 30035 Nìmes Cedex 1, France \\ ${ }^{b}$ G2R-UMR CNRS 7566, Université Henri Poincaré, 54506 Vandoeuvre-les-Nancy Cedex, France \\ 'CNRS-UMR 6118, Géosciences Rennes, Université de Rennes 1 - CNRS, campus de Beaulieu, Bat 15, 35042 Rennes Cedex, France \\ ¿IRSN - Institut de Radioprotection et de Sûreté Nucléaire, Av. du Gen. Leclerc BP n¹7, 92262 Fontenay-aux-Roses, France
}

\section{A R T I C L E I N F O}

\section{Introduction}

Deep geological disposal of high-activity and long-period radioactive wastes in France is designed with a confinement system based on the multiplication of argillaceous and cement-bearing barriers called 'engineered barriers'. The role of these barriers is to avoid the release of radio-elements into the biosphere, as well as to prevent the potential addition of external fluids to the waste materials. In a deep clay-rich medium, cementitious materials are expected to account for most of the building structures, the packages containing waste, as well as the cell grouts or plugs. These cementitious materials will be emplaced at the immediate contact with the natural argillaceous formation and/or the bentonite plugs.

\footnotetext{
* Corresponding author. Tel: +33 (0)4 667099 73; fax: +33 (0)4 66709989 . E-mail address: isabelle.techer@unimes.fr (I. Techer).
}

Hydrolysis of cementitious phases is known to produce hyper-alkaline pore fluids with pHs ranging from 10 to 13.5 (Atkinson et al., 1985; Berner, 1992; Hewlett, 1998), whereas natural argillaceous settings are characterized by a nearly neutral $\mathrm{pH}$. Numerous studies have been performed in the last decades to assess interactions in such a chemical disequilibrium context, with the specific aim of identifying their effect on the confinement material properties. These studies have been based mainly on evaluation of mineralogical and petrophysical changes during propagation of high-pH fluids in claystones, either by laboratory experiments (Ramirez et al., 2002, 2005; Fernandez et al., 2009b; Dauzères et al., 2009, 2010a), computer modeling (Savage et al., 2002; De Windt et al., 2004; Gaucher and Blanc, 2006; Fernandez et al., 2009a), or characterization of natural and engineered analogues (Khoury et al., 1985; Linklater et al., 1996; Milodowski et al., 2001; Techer et al., 2006; Tinseau et al., 2006; Fourcade et al., 2007; Elie et al., 2007). They 
have allowed identifying the mineral transformations that have occurred in claystones and the cementitious materials during interaction with alkaline fluids over various time sequences.

In order to better constrain the reaction processes induced by alkaline fluids/argillite interaction and to specify the geometry of the system, this study will focus on a combined acquisition of mineralogical and geochemical data from contact zones located between a cement paste or a concrete and a natural argillite after a 15-a interaction. This approach is based on the characterization of an engineered analogue that was described preliminarily by Tinseau et al. (2006) and modeled by De Windt et al. (2008). This engineered analogue, called the DM borehole, is located in the Tournemire Experimental Platform (Aveyron, France) and is to a 15-a old borehole crosscutting the Toarcian argillite formation and sealed with concrete. The over-coring of the borehole exhibits the natural claystone in contact with a CEM II hardened cement paste or with a CEM II concrete. A mineralogical and geochemical characterization of samples collected either next to or away from the cement-bearing materials, at various depths in the borehole is presented. In combination with SEM and TEM investigations, $\mathrm{Sr}, \mathrm{O}$ and $\mathrm{C}$ isotope systems are used to constrain the propagation of alkaline fluids generated by the cement into the clay medium: limited alkaline fluid/rock interactions that cannot be identified by mineralogical observations due to the relative high detection limit will be discussed on the basis of isotope modeling based on distinguishable $\mathrm{C}$ and $\mathrm{Sr}$ isotope compositions in the clays and in the cement paste and concrete (Techer et al., 2006; Fourcade et al., 2007).

\section{Description of the sampling site and samples}

The study area is located in the Tournemire Experimental Platform of the French Institute for Radioprotection and Nuclear Safety (IRSN) located in Aveyron (SE France). The platform is devoted to multi-disciplinary research on the feasibility of deep geological disposal of radioactive wastes. The site was initially constructed between 1882 and 1888 as a train tunnel of several hundred meters beneath the 'Plateau des Causses'. Secondary galleries were then excavated horizontally from the tunnel between 1996 and 2008. The underground structures crosscut a $200-\mathrm{m}$ thick argillite Toarcian formation from South to North which is composed mainly of phyllosilicates (40-50 wt.\% of illite, chlorite, kaolinite and illite/ smectite mixed-layers), calcite, dolomite, $\mathrm{K}$ and $\mathrm{Na}-\mathrm{Ca}$ feldspars, pyrite and quartz (Boisson et al., 2001; Tinseau et al., 2006). In 1990, exploration boreholes were drilled from the tunnel for

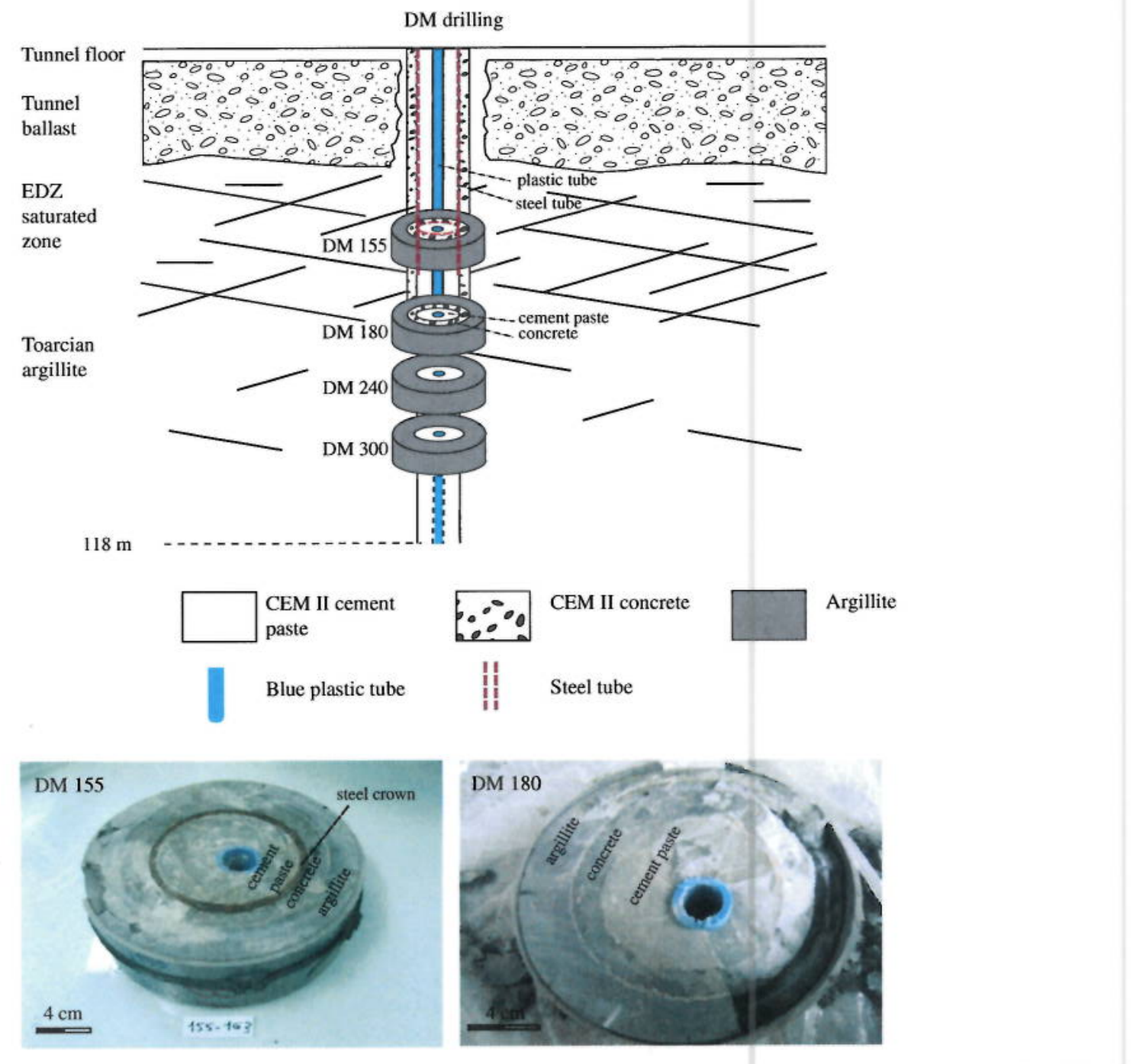

Fig. 1. Scheme of the DM borehole in the Tournemire Experimental Platform. Location of the studied layers along the borehole: DM155, DM180, DM240 and DM300 and representation of the cementitious materials (CEM II concrete or cement paste) in contact with the argillite. The images are from DM155 and DM180 sections. 
hydro-geological characterization of the basement formations, in some cases downwards into the Toarcian argillite over a depth interval of several hundred meters. Soon after these hydro-geological measurements, the boreholes were filled with CEM II cement paste and concrete. The deeper parts of the boreholes were entirely filled with cement paste, which was mixed with concrete in the upper meters below the tunnel floor (Fig. 1). Over-coring of these boreholes results in contacts between argillite and cementitious materials that can be expected to be similar in a deep geological waste disposal. Of these boreholes, Tinseau et al. (2006) focused on the DM-borehole that was over-drilled by $3 \mathrm{~m}$, for a mineralogical characterization of the cementitious materials and the claystone in contact. The samples of the present study come from four layers located between $1.55 \mathrm{~m}$ and $3.00 \mathrm{~m}$ of this over-core (Fig. 1). The four sets of samples are labeled as a function of their depth location: $1.55 \mathrm{~m}$ (DM155), $1.80 \mathrm{~m}$ (DM180), $2.40 \mathrm{~m}$ (DM240) and $3.00 \mathrm{~m}$ (DM300). The layers are located in the excavation disturbed zone (EDZ) of the tunnel that can be considered to be pore-fluid saturated as it is drained by the Cernon fault (Fig. 1). The deepest layer (DM300) is, however, expected to be less affected by the EDZ, and thus less saturated.

Each sample set consists of argillite and cement paste or concrete, which were collected along a profile perpendicular to the axis of the core. In sample DM155, the center of the core corresponds to a white cement paste (CEM II-A-LL, Portland cement base material with calcareous wt.\% between 6 and 20) surrounded by a steel crown and a $\sim 1.5 \mathrm{~cm}$ thick concrete crown (CEM II) in contact with the argillite (Fig. 1). This sample was considered by De Windt et al. (2008) for reactive transport modeling using the HYTEC code. In sample DM180, the same configuration occurs but without the steel crown (Fig. 1). A $2.5-2.8 \mathrm{~cm}$ thick crown of argillite was observed surrounding the concrete in these two samples (Fig. 1). Samples DM240 and DM300 show a core consisting of a fine-grained cement paste (CEM II) surrounded by $5-6 \mathrm{~cm}$ of argillite. The cement paste is white colored, shows a fine-grain chalky texture in sample DM240, and is more indurated with inclusion of gray zones in sample DM300. The argillite crowns are thicker in these layers $(5.5-6 \mathrm{~cm})$. Argillites collected in the deep layers (DM240, DM300), and far from cement paste/concrete interface, will be considered as undisturbed reference materials.

Mineralogical and geochemical characteristics of argillite located away from or next to the cement paste/concrete interface were investigated at two scales: (1) in the rock matrix (labeled P1) and (2) in micro-cracks crosscutting the claystone perpendicular to the cement paste/concrete interface (labeled P2). These micro-cracks were more numerous in the upper layers of the borehole and very discrete in the deeper ones. Along P1, the argillite was sampled continuously in sections perpendicular to the central axis of the core, every $2-4 \mathrm{~mm}$ over about $20 \mathrm{~mm}$. Some samples were collected at the external limit of the profiles as undisturbed references. Although no secondary mineral recrystallization was detected to the naked eye along P2 (even if a bright
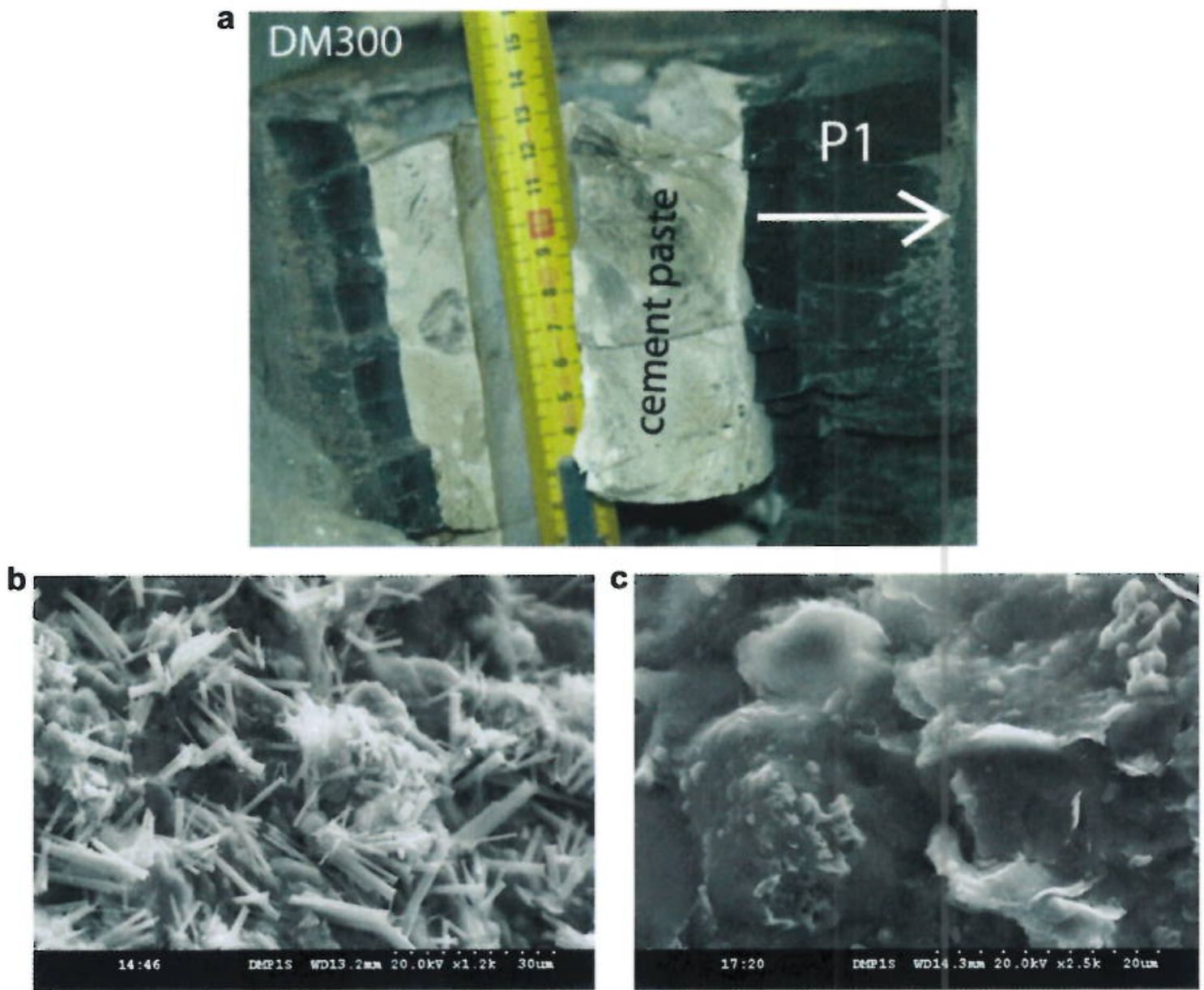

Fig. 2. (a) Macroscopic observation of DM300 section and representation of the P1 studied profile crosscutting the Toarcian argillite in contact with the cement paste; the $15 \mathrm{~mm}$ thick dark band is well outlined at the interface of the two materials. (b and c) SEM images showing 'needle-like' ettringite crystals (b) and a Si-Ca rich gel in the dark band matrix (c). 
I. Techer et al./

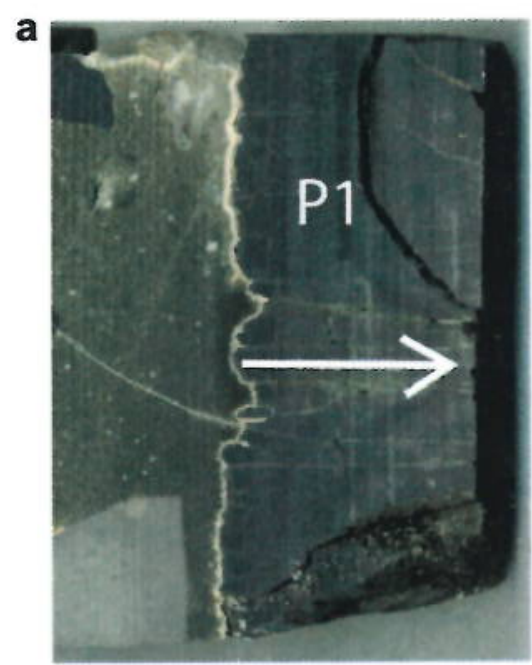

c
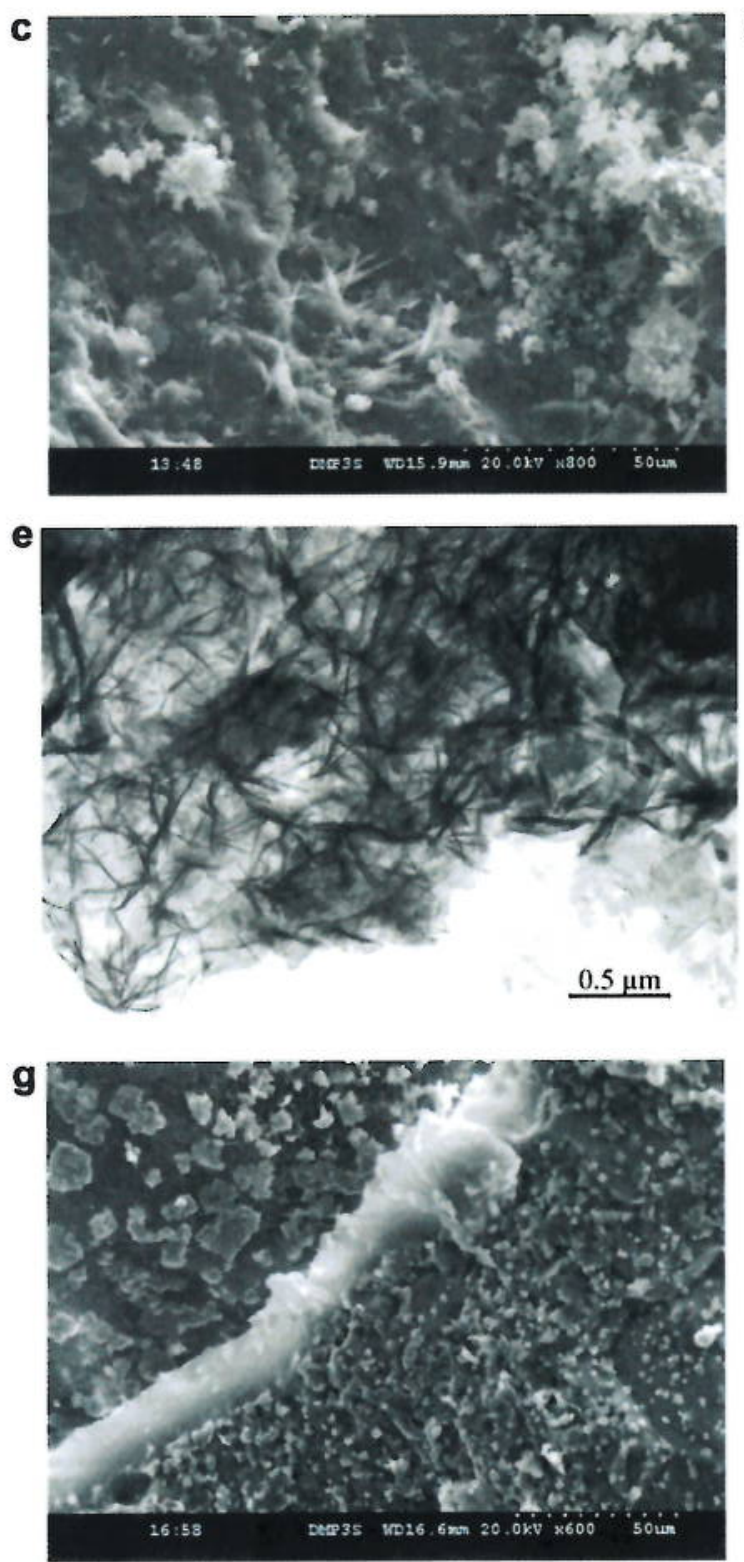
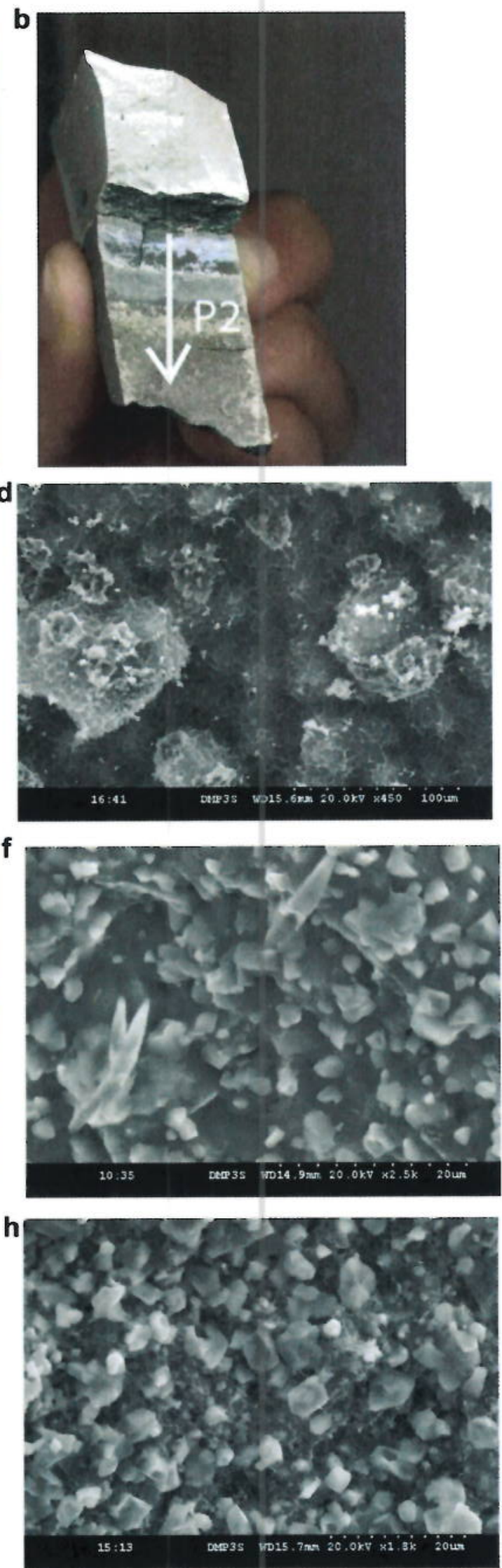
aspect and specific blue colors were noticeable in some cases), the contact surfaces were carefully scraped to collect any discrete secondary minerals. Despite all precautions, the possibility of contamination by host argillite material cannot be ruled out for these samples, especially considering the small amount of infilling materials.

\section{Analytical procedures}

\subsection{Mineralogical characterization}

The argillite samples were crushed and sieved for mineral analysis of the whole-rocks and of the $<2 \mu \mathrm{m}$ clay fractions by X-ray diffraction (XRD). Measurements were performed using a Siemens D500 diffractometer operating at $40 \mathrm{kV}$ and $30 \mathrm{~mA}$ with a $\mathrm{Cu} \mathrm{K \alpha}$ radiation (MNHN, Paris, France). Some rock fragments were kept, C-coated and observed by scanning electron microscopy (SEM). The SEM was equipped with an energy-dispersive spectrometry system (Hitachi S-3500, Oxford-Isis EDS) (IRSN, Paris, France) for qualitative overall or localized analyses. Transmission electron microscopy (TEM) was also used to examine the morphology of mineral grains that were added to alcohol suspensions and settled onto perforated carbon grids. The TEM was coupled with an energy dispersive X-ray analyser (TEM-EDX) to determine semi-quantitative chemical compositions (Philips CM20) (SCMEM, Nancy, France). Analyses were carried out in nanoprobe mode with a probe diameter of $10 \mathrm{~nm}$ and $40 \mathrm{~s}$ counting time. Values for the constant $k$ were determined using standards.

\subsection{Whole-rock chemical analyses}

The argillite samples collected along the $\mathrm{P} 1$ profile of samples DM240 and DM300 were crushed for chemical analyses. The DM155 and DM180 profiles were not investigated at this scale due to their short length. For the whole-rock, the compositions of major, trace and rare-earth elements (REE) were determined by ICP-AES and ICP-MS (SARM, Nancy, France). Approximately $100 \mathrm{mg}$ of ignited rock powders were fused with $\mathrm{Li}_{2} \mathrm{BO}_{4}$ in an $\mathrm{Ar}-$ atmosphere and dissolved in $25 \mathrm{~mL}$ of $\mathrm{HNO}_{3}$-glycerine solution, for analysis. The relative standard deviations for the major, trace and rare-earth elements were $3 \%$ and $5 \%$ and at $8 \%$, respectively.

\subsection{Extraction of soluble phases: chemical and isotopic analyses}

In most cases, $30-60 \mathrm{mg}$ of rock or mineral powder were used to determine the total elementary, $\mathrm{Sr}, \mathrm{O}$ and $\mathrm{C}$ isotope compositions. However, in some cases the powder amount was not sufficient for a complete analysis, as for sampling in micro-cracks (P2). For these samples, only $\mathrm{Sr}$ isotopic measurements were performed.

For the $\mathrm{C}$ and $\mathrm{O}$ isotopic procedure, the carbonate fraction (1-10 mg) was allowed to react with $100 \%$ orthophosphoric acid at $50^{\circ} \mathrm{C}$ (McCrea, 1950) using $\alpha(0) \quad \mathrm{CO}_{2} / \mathrm{CaCO}_{3}$ (extraction) $=1.009306$ considering that the carbonate phase consisted entirely of calcite despite identification of some dolomite in the Toarcian argillite matrix (Tinseau et al., 2006). The carbonate content was determined by measuring the $\mathrm{CO}_{2}$ partial pressure during the reaction, with an uncertainty at $0.5 \mathrm{wt}$.\%. The $\mathrm{CO}_{2}$ was then purified from $\mathrm{H}_{2} \mathrm{~S}$ released during interaction with orthophosphoric acid and the sulfides disseminated in the argillite, by reaction with $\mathrm{Ag}_{3} \mathrm{PO}_{4}$ for $5 \mathrm{~min}$ at ca. $50^{\circ} \mathrm{C}$. The isotopic analyses were carried out on a VG SIRA 10 triple collector mass spectrometer (Géosciences Department, University of Rennes, France), and are reported using the conventional $\delta$ notation vs. SMOW (for 0 ) and PDB (for C). Analyses were made at distinct periods so that specific corrections were applied to the results according to replicate analysis of the internal carbonate standard Prolabo Rennes and NBS 19 reference material. The average uncertainties were estimated at $<0.1 \%$ for $\delta^{13} \mathrm{C}$ and at ca. $0.1 \%$ for $\delta^{18} \mathrm{O}$.

For the $\mathrm{Sr}$ isotopic determinations, the soluble material, also referred to as leachate, was extracted by reacting the mineral powders with $1 \mathrm{~N}$ acetic acid, with an acid/rock ratio of 0.02 and a leaching time of about $5 \mathrm{~min}$ at room temperature. The leachates were then separated by centrifugation and dried before dissolution in $\mathrm{HNO}_{3}$. Strontium separation was performed on the Eichrom Srresin, following the Pin et al. (2003) method. Strontium was loaded on a Ta-filament and the ${ }^{87} \mathrm{Sr} /{ }^{86} \mathrm{Sr}$ isotopic ratio was measured by solid-source thermal ionization mass spectrometry (Finnigan TRITION TI) (University of Nîmes, France). Approximately 90 ratios were measured for each aliquot to ensure an analytical error $(2 \sigma)$ of about $5 \times 10^{-6}$. The external reproducibility of the isotopic measurements was controlled by repetitive analysis of the NBS987 standard providing a mean value of $0.710258 \pm 2 \times 10^{-6}(2 \sigma)$.

A second aliquot of the mineral powders was treated by an identical acetic acid leach for the determination of the major elements and $\mathrm{Sr}$. The same 'acid/powder' ratio and reaction time were used for all samples as before. The leachates were analyzed by ICPAES and ICP-MS following a procedure described by Samuel et al. (1985) (LhyGeS, University of Strasbourg, France). Reproducibility and accuracy tests were performed routinely by a systematic analysis of the BE-N and GL-O standards for all elements of each data set. The relative standard deviation for $\mathrm{Ca}$ was $3 \%$ for $\mathrm{Ca}$, and $5 \%$ for the other elements.

\section{Results}

The macroscopic observation of the "cementitious material/ argillite' system collected along the DM borehole provides determining information about the scales of transformations. The first optical change observed in the system corresponds to the occurrence of a thin white crust at the concrete/argillite interface (in samples DM155 and DM180), whereas no such crust is detected at the cement paste contact (samples DM240 and DM300). Next to the cement paste and concrete, peculiar features are observed in the argillite in a $10-15-\mathrm{mm}$ thick zone. There, the claystone is characterized by a dark color and an isotropic appearance (Fig. 2a). The dark zone is thicker in the deep layers $(15 \mathrm{~mm}$ in DM300) than in the upper ones (10 mm in DM180). It is less evident in sample DM155 at the contact with the concrete (DM155) in which 2-mm thick dark bands parallel the concrete interface in the clay-rich matrix; they delineate a supposed disturbed zone about $10 \mathrm{~mm}$ thick (Fig. 3a). This upper layer of the borehole also

Fig. 3. ( $\mathrm{a}$ and b) Macroscopic observations of the DM155 section and representation of the P1 and P2 studied profiles crosscutting the Toarcian argillite in contact with concrete: $2-\mathrm{mm}$ thick dark bands parallel the concrete interface in the clay-rich matrix (a-P1 scale) and a zonation is clearly visible along 10 mm open discontinuities underlined by a specific bluish color (b-P2 scale). (c-h) SEM and TEM images obtained in the various zones of the P2 profile: (c) acicular ettringite crystals in the first zone, (d) $\mathrm{C}-\mathrm{S}-\mathrm{H}$ honeycomb structures in the second zone that was identified by the more pronounced bluish color, (e) these $\mathrm{C}-\mathrm{S}$ - $\mathrm{H}$ phases were characterized by a foil-like morphology by TEM, $(\mathrm{f})$ sub-automorphous calcite and celestine were also observed in this second zone, $(\mathrm{g})$ a smooth Ca-Si rich white band marked the boundary between the second and the third zone, (h) calcite and C-S-H neoformations in the fourth zone. (For interpretation of the references to color in this figure legend, the reader is referred to the web version of this article.) 

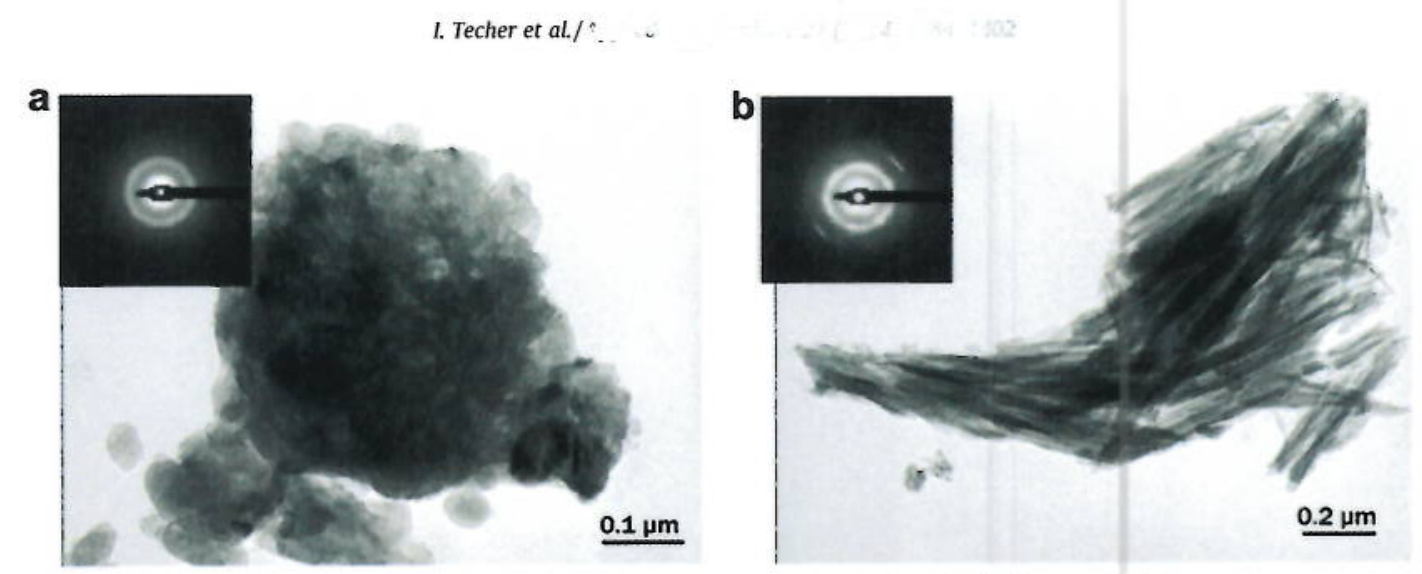

C
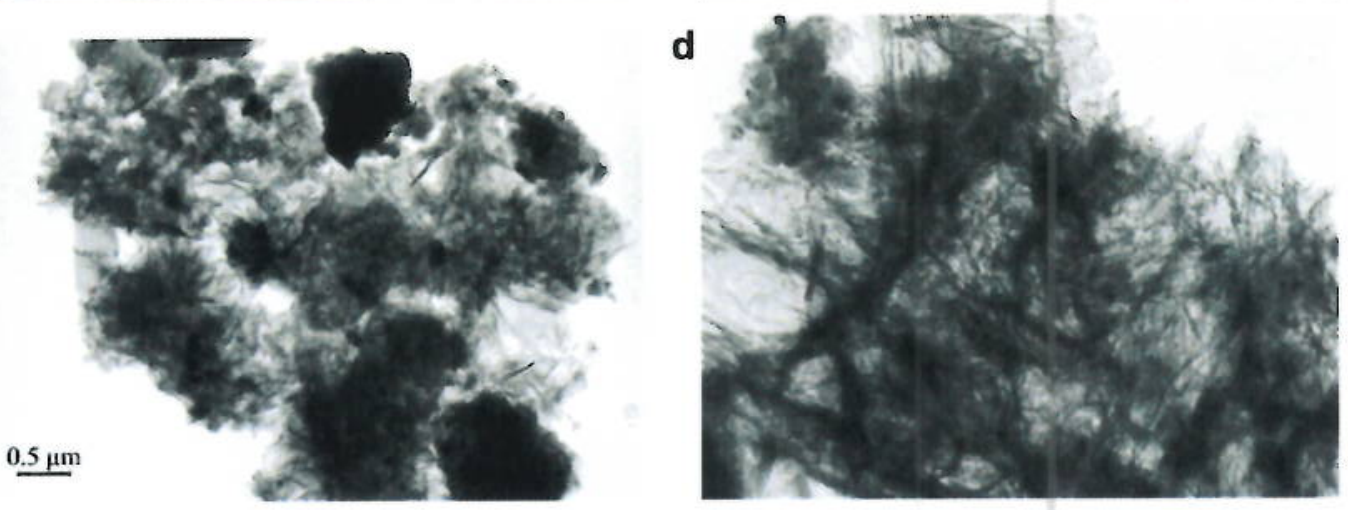

Fig. 4. (a-c) TEM images of C-S-H phases observed in the concrete and cement paste materials: (a) identified with a fluffy appearance (flakes) and diffuse SAED rings in the concrete, (b) characterized either with fiber morphology and a SAED showing a secondary discontinuous ring with a periodicity of $0.18 \mathrm{~nm}$ in the DM300 and DM240 cement paste, (c) or with foil-like structures. (d) TEM image of the C-S-H phases observed in the thin crust at the concrete/argillite interface with morphology mixing thin fibers, foillike and granular forms.

outlines many open discontinuity surfaces corresponding to a decompression process following the claystone coring. Along these plan surfaces (P2 scale), a zonation is clearly visible over about $10 \mathrm{~mm}$ (Fig. 3b), underlined by a specific bluish color. The mineralogical and chemical characteristics of so-defined 'cementitious material/argillite' system is described below.

\subsection{Cement paste and concrete}

The CEM II cement paste and the CEM II concrete display similar XRD patterns and are mainly composed of portlandite, calcite and ettringite. Calcium silicate hydrates $(\mathrm{C}-\mathrm{S}-\mathrm{H})$, which are typical hydration products of cement, are not detected by XRD in the studied materials. Instead, they are observed by TEM as non-diffracting phases, mainly with 'fluffy flakes' and 'foil-like' morphologies (Fig. 4a-c). Such non-diffracting phases are also identified in the thin crust sampled between the concrete and the argillite, together with ettringite and $\mathrm{CaCO}_{3}$. The $\mathrm{C}-\mathrm{S}-\mathrm{H}$ phases appear in this crust with morphologies that mix thin fibers, foil-like forms and granular forms (Fig. 4d). The three isomorphs of $\mathrm{CaCO}_{3}$ are also detected by XRD (calcite $55 \%$, aragonite $30 \%$ and vaterite $15 \%$ ) in the rim.

The cement paste and the concrete are distinguishable on the basis of their mineral contents and their geochemical characteristics. The CEM II concrete is identified by carbonate contents ranging from 19 to $33 \mathrm{wt} . \%$ that are related to the intrinsic properties of the material and its aggregate heterogeneity (Fig. 5). The cement paste is more homogeneous with a mean $\mathrm{CaCO}_{3}$ content of $39 \mathrm{wt} . \%$, which is expected for a CEM II-A-LL cement base material (Fig. 5). However, one sample of this cement paste from the DM300 layer yields an unexpected composition with a low $\mathrm{CaCO}_{3}$ value of 26 wt.\%. This heterogeneity may results from addition of gray and indurated materials observed in the layer, probably induced by the infilling of the borehole by the cement.

The $\delta^{13} \mathrm{C}$ values are low in all cementitious materials, ranging from $-8.3 \%$ to $-13.2 \%$ (Table 1 ). Such data belong to the domain defined for various mortars and cements (Letolle et al., 1992). The DM240 cement paste yields the lowest values $(-11.2 \%$ and $-13.2 \%$ ), whereas the highest $(-8.3 \%$ ) is obtained on the gray and indurated part of the DM300 cement paste (Fig. 6). In contrast, the $\delta^{18} \mathrm{O}$ values are identical in the concrete and cement paste, with a mean value of $19.4 \%$, except the DM 300 cement paste characterized by a low $\delta^{18} \mathrm{O}$ value of $16.5 \%$ (Table 1, Fig. $6 \mathrm{c}$ ).

The dilute acid leachates extracted from cement paste and concrete are mainly calcitic, and also contain significant amounts of $\mathrm{Si}, \mathrm{Al}$ and $\mathrm{Fe}$ (Table 3). Concrete and cement paste leachates show distinct compositions: in comparison to the concrete leachates, those of the cement paste are enriched in $\mathrm{Ca}, \mathrm{Si}$ and $\mathrm{Al}$, yet they are depleted in $\mathrm{Sr}$ contents $\left(230-340 \mu \mathrm{g} \mathrm{L}^{-1}\right.$ relative to $380-$ $\left.400 \mu \mathrm{g} \mathrm{L}^{-1}\right)$. As a result, the leachates of the cement paste are more concentrated than those from concrete $\left(760-1360 \mathrm{mg} \mathrm{L}^{-1}\right.$ and $635 \mathrm{mg} \mathrm{L}^{-1}$, respectively). The previously mentioned DM300 gray cement paste is quite specific with a leachate enriched in all elements. Similarly, variable $\mathrm{Sr}$ isotope ratios are obtained regardless of the nature of the cementitious material (Table 1; Fig. 7): the concrete is identified by high ${ }^{87} \mathrm{Sr} /{ }^{86} \mathrm{Sr}$ ratios ranging between 0.708352 and $0.708380\left( \pm 6 \times 10^{-6}\right)$, whereas the cement paste displays relatively lower ratios (from 0.708122 to 0.708308 ). The ratios are scattered in the DM240 cement paste and are fairly homogeneous in the DM300 cement paste with a mean value of $0.708260\left( \pm 5 \times 10^{-6}\right)$ (Table 1$)$. No specific composition is seen in the special DM300 gray cement paste sample mentioned above. 


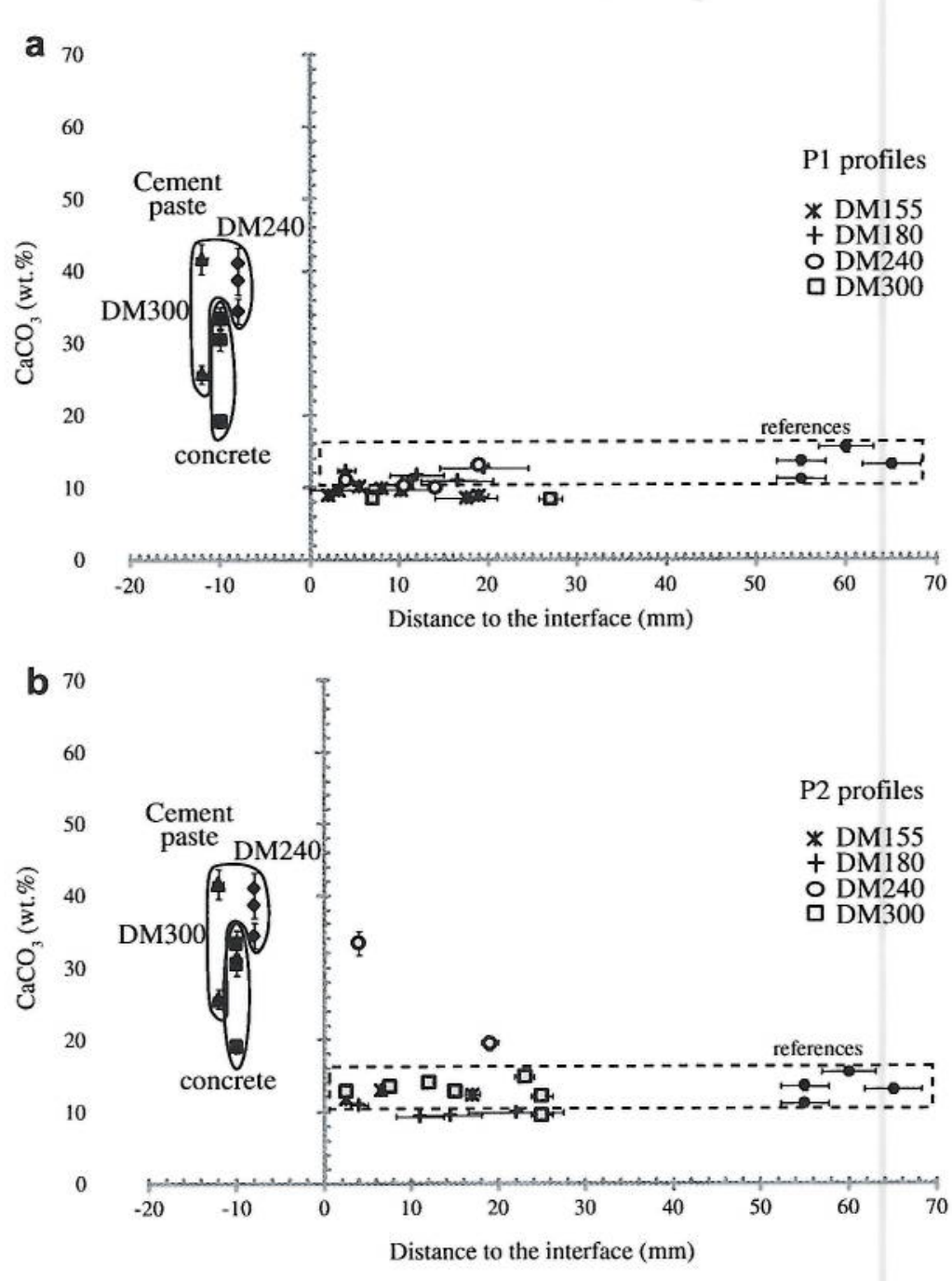

Fig. 5. Calcite content $\left(\mathrm{CaCO}_{3}\right.$ wt.\%) of the CEM II cement pastes and concrete and of the argillite in the matrix along P1 profiles (a) and in the micro-cracks along P2 profiles (b).

\subsection{The Toarcian argillite}

\subsubsection{Variations in the matrix ( $P 1$ scale)}

No significant changes are shown by XRD in the mineral composition of the Toarcian argillite along the P1 profiles. The claystone is characterized next to or away from cementitious materials by the same mineral sequence with predominant phyllosilicates (illite, micas, kaolinite, and chlorite), carbonates (calcite, dolomite), $\mathrm{K}$ and $\mathrm{Na}-\mathrm{Ca}$ feldspars and pyrite. The clay-fraction assemblage determined after air-drying and ethylene-glycol treatment is also similar in all samples, consisting of chlorite, non-expandable illiteor mica-type dioctahedral layers and kaolinite. A broad diffraction domain observed between 11 and $12 \AA$ on the air-dried samples is assigned to an illite/smectite mixed-layer mineral. Alternatively, distinct mineralogical features are visible by SEM in the 10-15$\mathrm{mm}$ thick dark zone when compared to the reference claystone. Next to the contact, large amounts of ettringite crystals are identified as more or less isolated acicular or 'needle-like' crystals (Fig. 2b). Throughout the entire zone, the structure of argillite appears denser and is less recognizable due to the occurrence of a SiCa rich gel, celestine, neoformed calcite and C-S-H phases (Fig. 2c). These latter phases are detected mainly by TEM based on their diffraction patterns and their foil-like morphology. These changes are close to those expected from the modeling (De Windt et al., 2008).
The chemical composition of the argillite whole-rock appears quite constant along the two longer profiles (DM240 and DM300) (Table 2). Only the 18-20-mm thick zone next to the interface with the cement paste shows slight changes: a clear and continuous increase in the $\mathrm{CaO}$ content progressing towards the cement paste, which is negatively correlated with a slight decrease in the $\mathrm{K}_{2} \mathrm{O}$ content. The behavior of $\mathrm{MgO}$ is specific with a maximum value measured systematically at the external limit of the zone (18$20 \mathrm{~mm}$ ) (Table 2; Fig. 8). This chemically modified zone is also enriched in Cs, whereas it is depleted in $\mathrm{Sr}$ and to a lesser extent in REEs (Table 2; Fig. 8).

Major changes are observed in the chemical composition of the argillite leachates (Table 3; Fig. 9). Reference samples located far from cementitious material are characterized by calcitic leachates with minor amounts of $\mathrm{Si}, \mathrm{Al}, \mathrm{Mg}$ and $\mathrm{K}, \mathrm{Sr}$ contents of about $500 \mu \mathrm{g} \mathrm{L}^{-1}$ and total elementary contents in the solution of about $200 \mathrm{mg} \mathrm{L}^{-1}$. Relative to this reference, samples collected close to the concrete along the DM180 P1 profile show a decrease in the total elemental content of their leachates at the immediate contact with the cementitious material $\left(0-10 \mathrm{~mm} ; 180 \mathrm{mg} \mathrm{L}^{-1}\right)$. This decrease is mainly linked to a significant decrease in the $\mathrm{Ca}$ and $\mathrm{Sr}$ contents. A peak in $\mathrm{Mg}$ and $\mathrm{Al}$ amounts occurs roughly in the middle of the studied zone (Table 3; Fig. 9). The Sr isotopic results for the leachates of the reference samples are quite homogeneous with 
Tabia 1

Location of the samples along the DW over-core corresponding to $-155, \cdot 180,-240$ and $-300 \mathrm{~cm}$ layers with distances to the cetnent pastc/conerete interface. Stjontitum chenical and isotopic composilions of the leachates; $\mathrm{C}$ ancl $\mathrm{O}$ isotope compositions and $\mathrm{CaCO}_{3}$ wt.

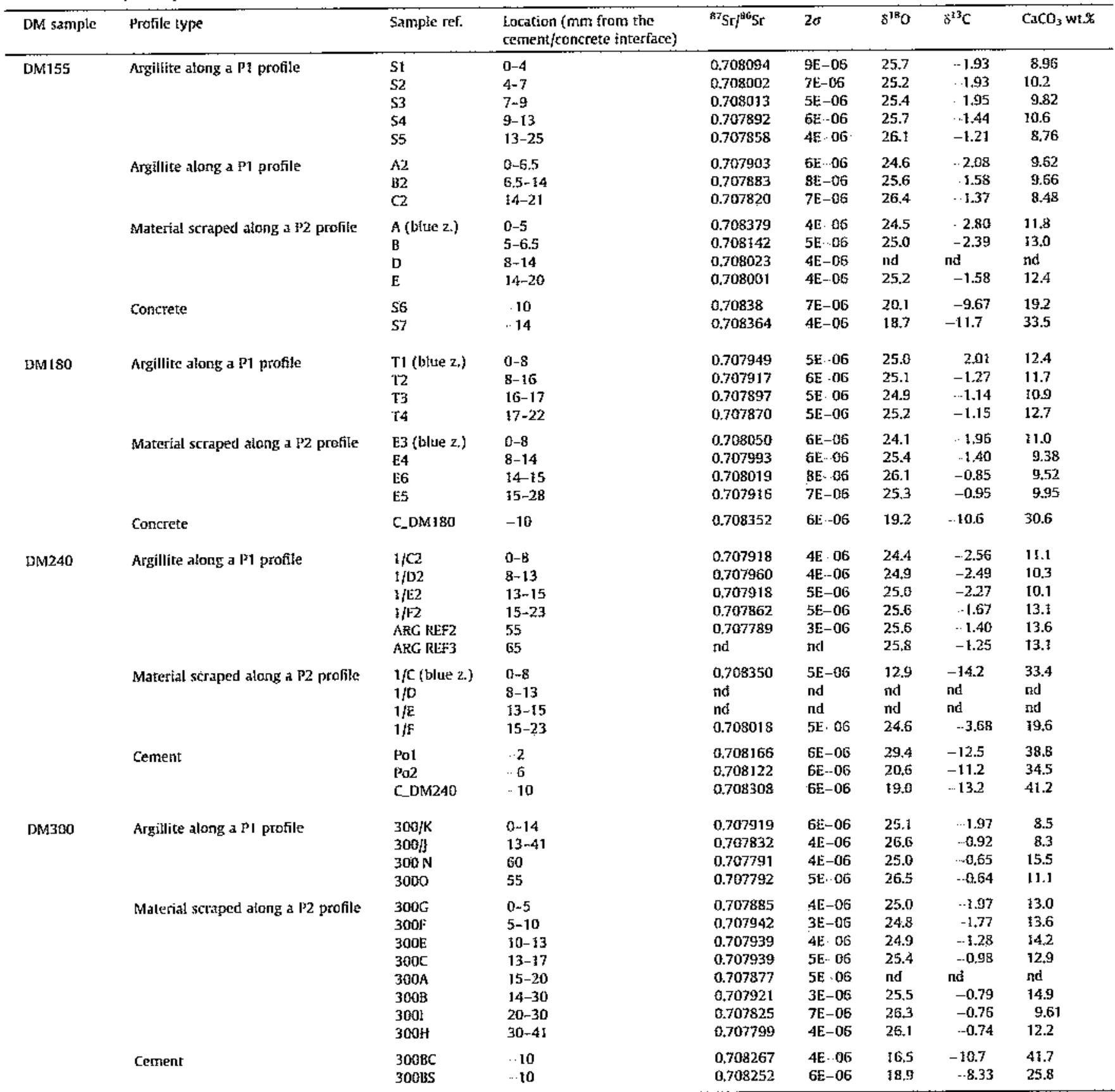

a mean ${ }^{87} \mathrm{Sr} /{ }^{\text {ans }} \mathrm{Sr}$ ratio of $0.707791 \pm 4 \times 10^{-6}$ (Fig. 7). This vatue agrees with previous measurements obtained on carbonates extracted from Toarcian argillite (Michel, 1999). Progressing towards the cement pasteiconcrete, the $\left.{ }^{37} \mathrm{Sr}\right|^{\mathrm{Bt}} \mathrm{SF}$ ratio of the leachates increases to a maximum vatue of $0.708094\left( \pm 9 \times 10^{-6}\right)$. This increase defines a 20-25-rmm thick transition zone between the interface of the cement paste and the concrete and the reference claystone (Fig. 7a).

The carbonate content of the reference argitlite samples is between 11 and 16 wt. $\%$ with a mean value of $13 \mathrm{wt} \%( \pm 2.2)$ (Fig. 5b). The $\delta^{13} \mathrm{C}$ and $\delta^{18} \mathrm{O}$ values for these carbonates are typical for marine materials tbetween $-0.64 \%$ and $-1.40 \%$ and between $25.0 \%$ and $26.5 \%$ respectively) at more than $20 \mathrm{mrn}$ from the cement paste/concrete interface (Fig. 10). When com parefl to these reference compositions, a slight deptetion in the $\mathrm{CaCO}_{3}$ content is visible in the argillite within the 20 min next to the cement paste/concrete interface, the values ranging around 10 wt. progressive decrease of the $\delta^{13} \mathrm{C}$ towards the cement pastejconcrete interface (from - - $1.40 \%$ to $-2.01 \%$ ). The P1 profile from sample DM240 shows the lowest $\delta^{13} \mathrm{C}$ value $(-2.6 \%)$ at the immediate contact with the cement paste (Fig. 6a). The $\delta^{18} \mathrm{O}$ remains constant along the profiles, ranging between $25 \%$ and $26.5 \%$. 

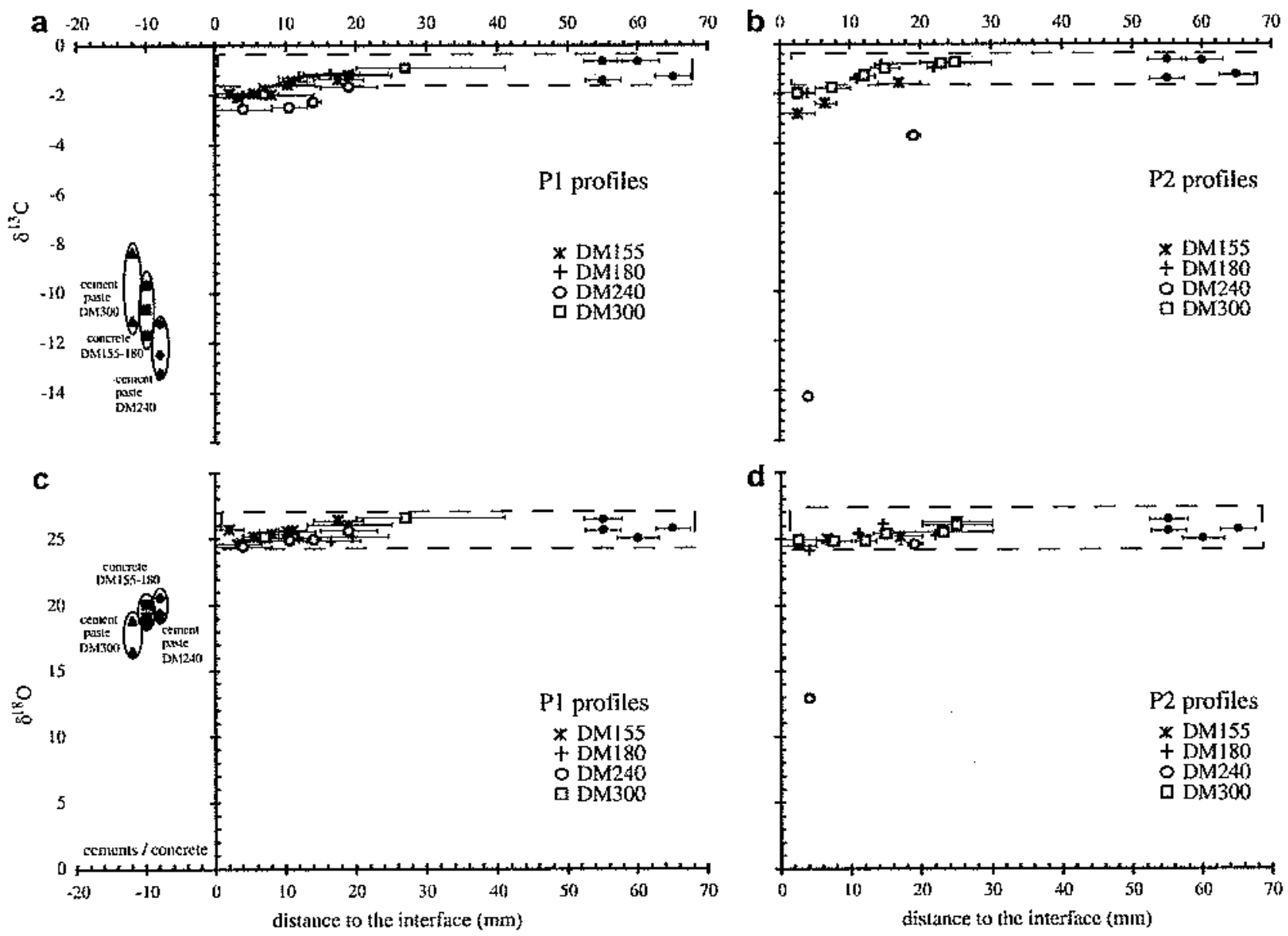

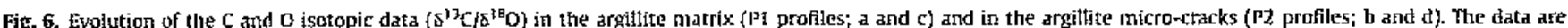
compared with values meastured in the coment paste and in line concrete.

\subsubsection{Variation at the micro-cracks (P2 scale)}

Along the $\mathrm{P} 2$ suffeces, the $10-\mathrm{mm}$ thick zone identified by a zonation and a blue color yields the same mineralogical assernblage as that defined in the reference claysrone by XRD. Only gypsum is observed as a specific phase. However, significant modifications become apparent when the samples are analyzed by SEM and TEM. These changes define five zones in the claystone. The first zone about $10-\mu \mathrm{m}$ thick is at the immediate contact with the cement paste or concrete. This zone is enriched in acicular ettringite crystals (Fig. 3c) that appear to decrease in number away from the contact. A second zone ( 500 -um thick) is characterized by the occurrence of $\mathrm{C}-\mathrm{S}-\mathrm{H}$ crystals, which can be identified by a folllike morphology by TEM and absence of diffraction (Fig. 3d and e). The blue color of the argitlite appears to be related with the amount of $\mathrm{C}-\mathrm{S}-\mathrm{H}$; sub-automorphous calcite and ceiestine are also observed in this zone (Fig. 3f). A third zone ( 500 -flm thick) is identified by a higher amount of calcite, and minor amounts of celestine and $\mathrm{C}-\mathrm{S}-\mathrm{H}$. The boundary between the second and third zones is marked by a smooth $\mathrm{Ca}-\mathrm{Si}$ rich white band (Fig. 3g). A fourth zone is defined over $500 . \mu \mathrm{H}$ by significant calcite neoformation and a minor amount of $\mathrm{C}-\mathrm{S}-\mathrm{H}$ grains ( $\mathrm{Fig}$. 3h); the last $300 \mu \mathrm{m}$ of this zone contains celcite cystals oriented towards the fifth zone. [n this Gfth zone, the texture of the Toarcian argillite is stifl recognizable and is slightly modified by some disoriented newlytormed calcite and some zngular K-feldspar suggesring an overgrowth.
Changes are also observed in the chemical composition of the leachates of powders scraped from argillite P2 plans. Two distinguishable trends are visible according to the location along the DW over-core. In the upper layer (DMI55), the total efementat content of the leachates decreases at the immediate contact with the concrete $\left(0-10 \mathrm{~mm} ; 153 \mathrm{mg} \mathrm{L}^{-1}\right)$. This decrease is mainly represented by a drop in Ca and Sr contents. Peaks in the amount of $\mathrm{Mg}$ and $\mathrm{Al}$ are also obseryed near the middle of the profile; these values being close to those observed along the $\mathrm{PI}$ profiles. In the deeper layer (DM300 sample) close to the rement paste ( $410 \mathrm{~mm}$ ), the total elemental content of the leachates is lighter than in the reference samples and increases towards the interface (finally reaching $289 \mathrm{mg} \mathrm{L}^{-1}$ telative to $200 \mathrm{mg} \mathrm{L}^{-1}$ in the reference argillite): this increase retates to an increase in nearty all the elaments (Table 3; Fig. 9). Along each studied $\mathrm{P} 2$ proftete, the ${ }^{87} \mathrm{Sr}{ }^{36} \mathrm{Sr}$ isotopic ratio of the leachates is higher than in the marine-like distal Toarcian samples (Fig. 7b), even at $25 \mathrm{~mm}$ fron the cement paste/concrete interface. At this incerface, the ${ }^{87} \mathrm{Sr}^{36} \mathrm{Sr}$ ratio increases from $0.707799\left(+5 \times 10^{-6}\right)$ to $0.708379\left( \pm 4 \times 10^{-6}\right)$.

No significant variation is visible in the carbonates when comparing the values of the scraped powder with those of the reference matrix (Fig. 5b). However, low $\delta^{13} \mathrm{C}$ values $(-1.8 \%$ to $-2.8 \%$ ) are measured in the carbonates mainly located within $11 \mathrm{~mm}$ of the cement/concrete interface. One exception is in the DM240 profite, where a clear increase in the $\mathrm{CaCO}_{3}$ content is found in miclo-cracks $(20-33 \mathrm{wt}$. $\%$ ). These carbonates are atso 
a
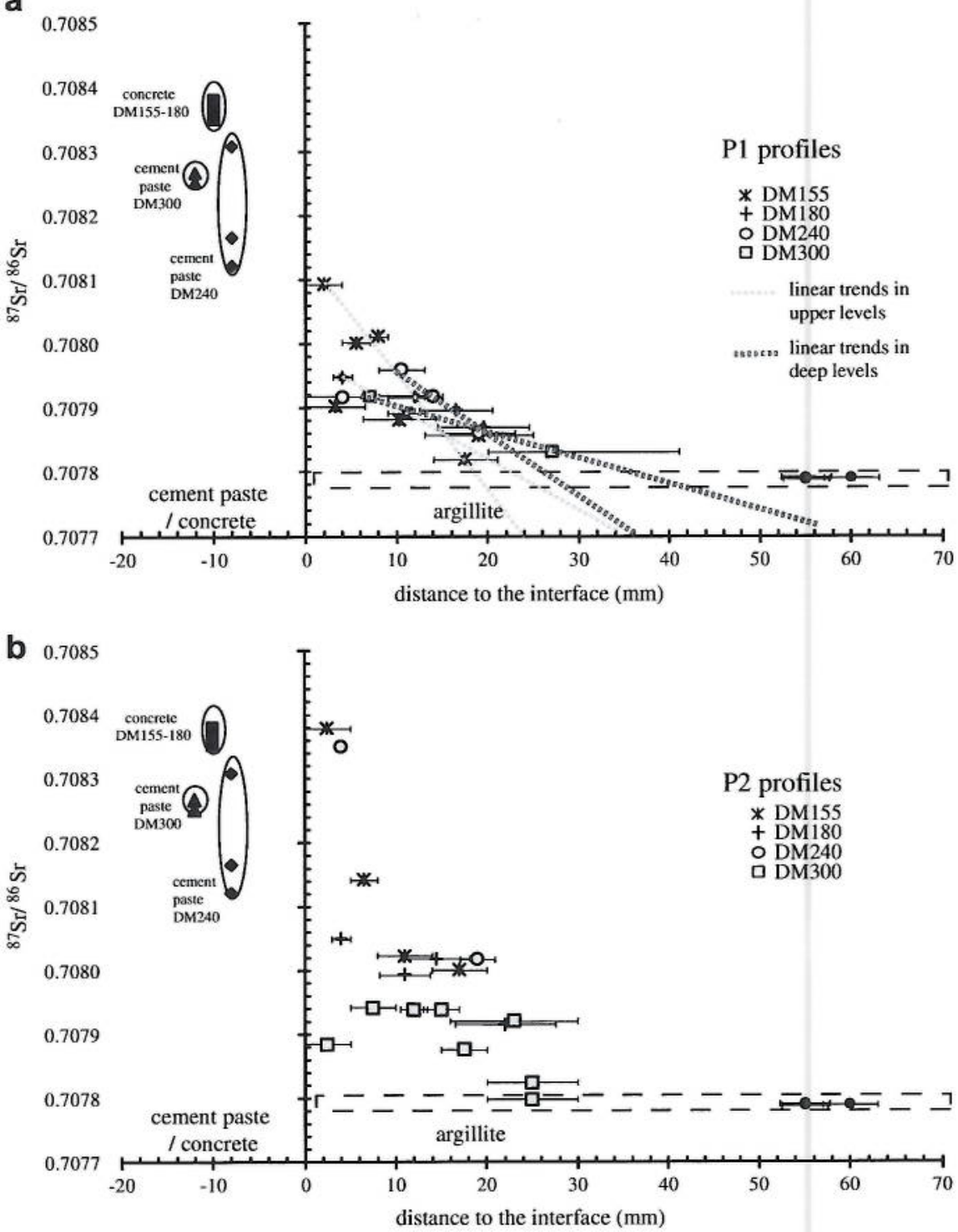

Fig. 7. Evolution of the $\mathrm{Sr}$ isotopic data $\left({ }^{87} \mathrm{Sr} /{ }^{86} \mathrm{Sr}\right.$ ) in the argillite matrix ( $\mathrm{P} 1$ profiles, a) and in the argillite micro-cracks ( $\mathrm{P} 2$ profiles, b). The data are compared with values measured in the cement paste and in the concrete.

strongly ${ }^{13} \mathrm{C}$ depleted with $\delta^{13} \mathrm{C}$ values as low as $-14.2 \%$ (Fig. $6 \mathrm{~b}$ ). The $\delta^{18} \mathrm{O}$ composition is also different in these newly-formed minerals, yielding lower values $(12.9 \%$ ) than those in the other samples (25-26.5\%) (Fig. 6d).

\section{Discussion}

5.1. On the interest of decoupling the data of carbonates and other soluble phases

In addition to the whole-rock analyses that are commonly performed in geochemical studies, the chemical and isotopic characteristics of selective extracted phases, carbonates and other soluble phases were examined. In fact, these phases are expected to be very sensitive to water/rock interaction, and even to record slight changes due to mineral dissolution and/or precipitation. They can, therefore, potentially record subtle and tiny disturbances
(Techer et al., 2009). The isotopic data (C, O, Sr) obtained on the cement paste/concrete and on the argillite outline distinct behaviors along the profiles. Before the processes responsible for these changes will be discussed, it is probably appropriate to detail the specifics of the two types of measurements. In fact, the $\mathrm{C} / \mathrm{O}$ and $\mathrm{Sr}$ isotopic data were obtained on two different fractions.

The $\delta^{13} \mathrm{C}$ and $\delta^{18} \mathrm{O}$ values were measured on the carbonate fraction of the rock powders that were extracted by reaction with orthophosphoric acid according to the equation:

$3 \mathrm{CaCO}_{3}+2 \mathrm{H}_{3} \mathrm{PO} 4 \Rightarrow 3 \mathrm{CO}_{2}+3 \mathrm{H}_{2} \mathrm{O}+\mathrm{Ca}_{3}\left(\mathrm{PO}_{4}\right)_{2}$

In argillite samples, this reaction results in the release of $\mathrm{CO}_{2}$ extracted mainly from calcite $\left(\mathrm{CaCO}_{3}\right)$ and dolomite $\left((\mathrm{Ca}, \mathrm{Mg}) \mathrm{CO}_{3}\right)$. Numerous and variable carbonate minerals are typically encountered in the specific environments of cement paste and concrete, predominantly represented by calcite (Atkins et al., 1991; Vieillard and Rassineux, 1992) and minor phases such as spurrite $\left(\mathrm{Ca}_{5}-\right.$ $\left.\mathrm{Si}_{2} \mathrm{O}_{8} \mathrm{CO}_{3}\right)$ and hydrotalcite $\left(\mathrm{Mg}_{0.75} \mathrm{Al}_{0.125}(\mathrm{OH})_{2}\left(\mathrm{CO}_{3}\right)_{0.125}\left(\mathrm{H}_{2} \mathrm{O}\right)_{0.5}\right)$ 
1. Tedier et at./

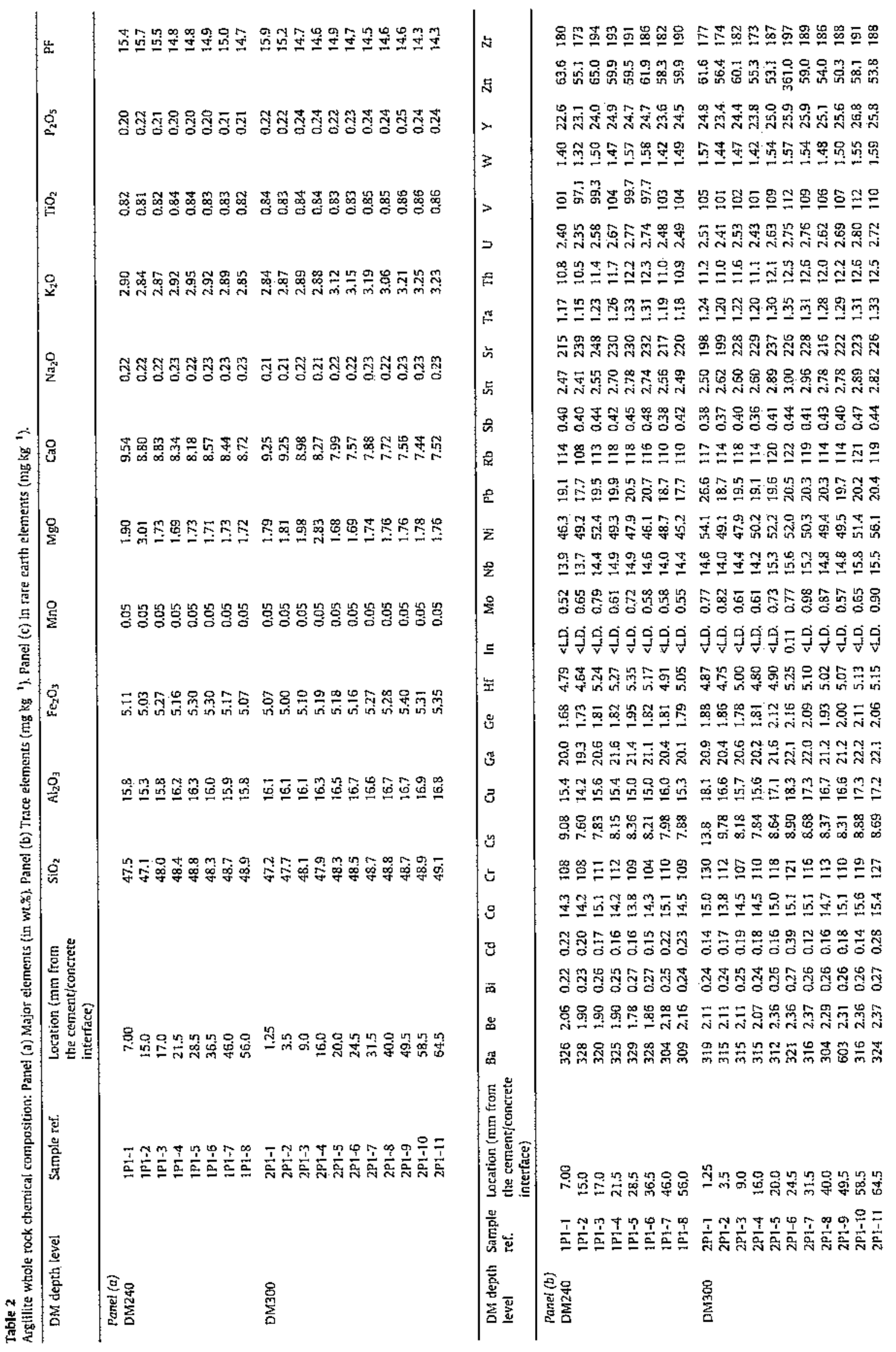


(Taylor, 1997). The alteration of these cementitious materials also leads to the formation of secondary carbonate phases such as new calcite and thaumasite $\left(\mathrm{Ca}_{6}\left[\mathrm{Si}(\mathrm{OH})_{3}\right]_{2}\left(\mathrm{CO}_{3}\right)_{2}\left(\mathrm{SO}_{4}\right)_{2} \cdot \mathrm{H}_{2} \mathrm{O}\right)$ that can be generated by extensive replacement of the $\mathrm{C}-\mathrm{S}-\mathrm{H}$ during coupled dissolution of sulfate and carbonate (Iden and Hagelia, 2003) at low temperature $\left(<18^{\circ} \mathrm{C}\right)$ for thaumasite. In the case of the DM study, the main components of the cement paste and concrete are portlandite $\left(\mathrm{Ca}(\mathrm{OH})_{2}\right)$, calcite $\left(\mathrm{CaCO}_{3}\right)$, ettringite $(3 \mathrm{CaOA}$ $\mathrm{l}_{2} \mathrm{O}_{3} 3 \mathrm{CaSO}_{4} 32 \mathrm{H}_{2} \mathrm{O}$ ) and amorphous $\mathrm{C}-\mathrm{S}-\mathrm{H}$. C-S-H and calcite were also observed as secondary minerals in the argillite close to the cement paste/concrete interface. Thus, the reported $\mathrm{C} / \mathrm{O}$ isotope signatures obtained by extraction of $\mathrm{CO}_{2}$ from the various samples essentially represent calcite.

The ${ }^{87} \mathrm{Sr} /{ }^{86} \mathrm{Sr}$ ratios were measured on whole-rock powders that were leached with a $1 \mathrm{~N}$ acetic acid solution. Such a procedure is expected to dissolve calcite, but also salts, sulfates and oxides, together with removal of pore water in most of the geological media (Clauer and Chaudhuri, 1995; Techer et al., 2009). In the case of the cement paste and concrete environments, other highly soluble phases can be extracted during this leaching procedure. Among the typical cementitious phases formed by hydration of cement paste and/or by alteration, C-S-H and portlandite - together with calcite - are known to be highly soluble and unstable under acid conditions (Hewlett, 1998). Decalcification of C-S-H and dissolution of portlandite are commonly observed when in contact with deionized water in ambient conditions (Planel et al., 2006). The two phases are known to be unstable in low pH environments (Berner, 1992; Vieillard and Rassineux, 1992; Adenot and Buil, 1992; Faucon et al., 1998; Le Bescop and Solet, 2006) and in clay-rich environments (Dauzères et al., 2009, 2010a,b). Thus, it can be expected that leachates may not only carry calcite but also $\mathrm{C}-\mathrm{S}-\mathrm{H}$ and portlandite. The complementary analysis of carbonates and leachates therefore represents an interesting issue to follow the occurrence of secondary cementitious phases and, as a consequence, the imprints of high-pH fluids.

\subsection{Alteration of the Toarcian argillite close to the cement paste/ concrete}

Thin rims of Toarcian argillite samples were cut parallel to the cement paste/concrete interface or scraped off discontinuity surfaces. For each analyzed zone, aliquots between 100 and $500 \mathrm{mg}$ were separated. Studying such small amounts of representative material increases the possibilities of technical and analytical artifacts. In order to overcome this issue, experiments were performed in duplicate, two sampling profiles being studied of the same borehole layer whenever possible.

In the deep layers of the DM borehole, at more than $5 \mathrm{~cm}$ from the interface with the cement, argillite measurements reveal $\mathrm{CaCO}_{3}$ contents (11-15.5 wt.\%), $\delta^{13} \mathrm{C}(-0.64 \%,-1.40 \%), \delta^{18} \mathrm{O}$ $(25 \%, 26.5 \%)$ and ${ }^{87} \mathrm{Sr} /{ }^{86} \mathrm{Sr}(0.70779)$ data that are typical of a marine undisturbed Toarcian claystone (Michel, 1999). These characteristics do not remain constant along the matrix profiles closer towards the cement paste or the concrete, and are different from those measured in the material scraped from micro-cracks close to the cementitious materials. Several changes are observed within ca. $20 \mathrm{~mm}$ of the argillite matrix (P1) and within ca. $25 \mathrm{~mm}$ of the micro-cracks (P2); these zones are referred to as the 'geochemical disturbed zone' (GDZ). The thickness of the GDZ is larger than that observed by mineralogical methods, which is limited to ca. 10$15 \mathrm{~mm}$ along the P1 scale and to $10 \mathrm{~mm}$ along the P2 scale. The extent of mineralogical transformations in the matrix (P1) increases with borehole depth and is more pronounced in layers that are less influenced by the train tunnel EDZ. When discontinuity plans (P2) do not occur in the clay-rich matrix, transformations seem to imprint the matrix (P1) more significantly. 
Table 3

Chemical composition of the argillite, cement paste and concrete leachates (in $\mathrm{mg} \mathrm{L}^{-3} ; 2 \sigma$ is $\pm 10 \%$ for both).

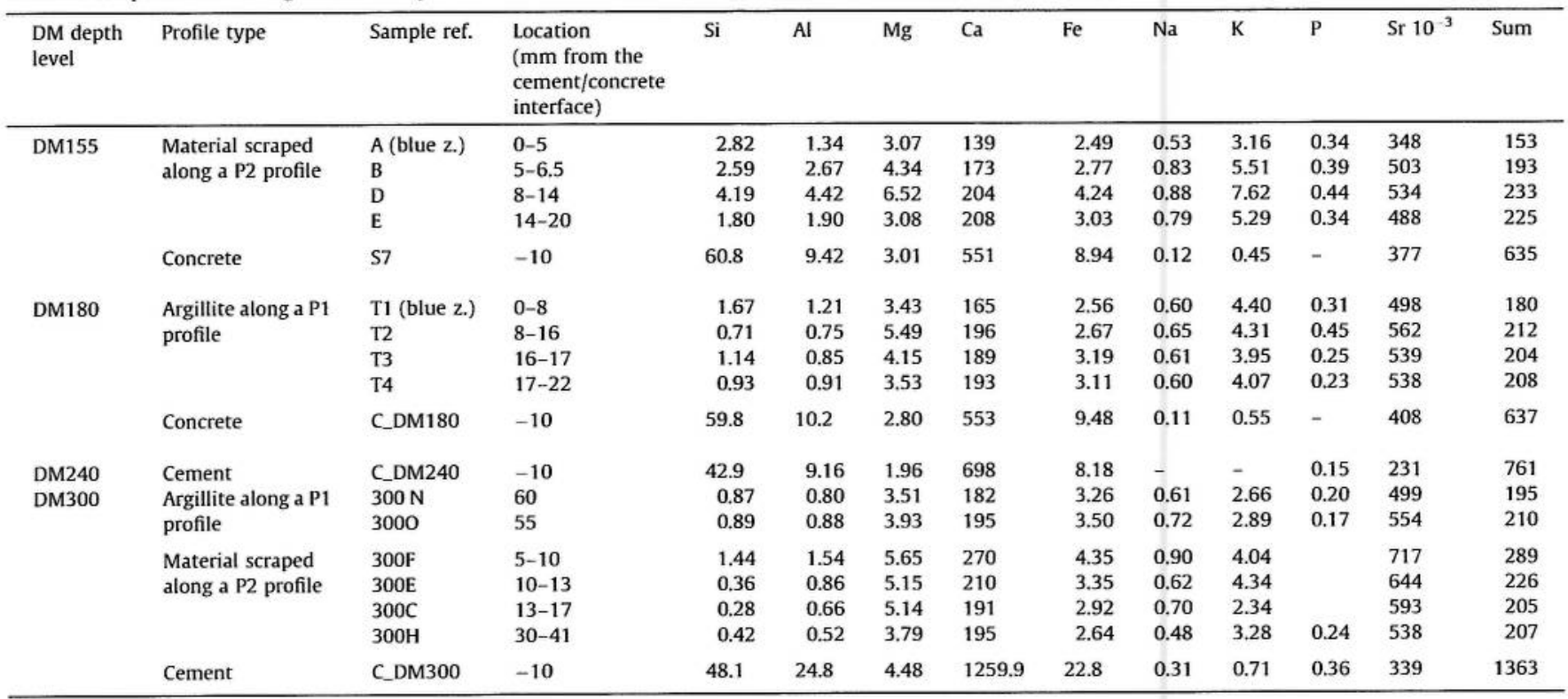

\subsubsection{In the matrix (P1 scale)}

The mineral transformation of the claystone within the 10-15$\mathrm{mm}$ thick dark zone corresponds mainly to neoformation of calcite, ettringite and $\mathrm{C}-\mathrm{S}-\mathrm{H}$ phases. The proportion of these neoformed crystals is, however, very limited as they cannot be detected by XRD means. Less than $5 \mathrm{wt}$.\% of each secondary mineral is expected in the disturbed matrix of the claystone. Despite this low variation intensity, the petrophysical characteristics of the rocks appears to have changed upon visual inspection. Gaboreau et al. (submitted for publication) investigated these changes by autoradiography and petrophysical measurements. They demonstrated a clogging of the claystone porosity in the dark zone that is likely linked to the mineralogical changes as defined here. On the basis of chemical and isotopic changes, a thicker disturbed zone is identified, reaching $20 \mathrm{~mm}$ in thickness. This GDZ is mainly characterized by higher $\mathrm{CaO}$ contents together with slightly lower carbonate proportions $(10-12 \mathrm{wt} . \%)$, in comparison to the reference state. This indicates slight carbonate dissolution together with neoformation of a calcitic phase. Carbonate dissolution can be expected in the clay-rich matrix at the contact with the cement paste if considering the Ca contents in the two materials at an initial state. In the presence of $\mathrm{KOH}$ and $\mathrm{NaOH}, \mathrm{Ca}^{2+}$ contents can be lower in the cement paste, than in the argillite (CHESS calculation) (Van der Lee, 1998). This difference can induce a $\mathrm{Ca}^{2+}$ flux from claystone to the cementitious material. If this dissolution of carbonates cannot be detected by means of the mineralogical techniques due to the low extent of the variation, the neoformation of the calcitic phase is supported by XRD, SEM and TEM, as well as by the occurrence of a Si-Ca rich gel. In the GDZ, the remaining carbonate phase does not yield marine isotopic signatures, but shows instead low $\delta^{13} \mathrm{C}$ values $(-2 \%$ to $-2.56 \%$ ) that are intermediate between those of marine carbonates $(-0.64 \%,-1.40 \%)$ and those of cement paste and concrete $\left(\delta^{13} \mathrm{C}=-8 \%\right.$ to $\left.-13 \%\right)$. Fourcade et al. (2007) demonstrated that in alkaline conditions, such as those produced during cement paste and concrete alteration, very low $\delta^{13} \mathrm{C}$ carbonates (labeled hereafter as 'cementitious carbonates') can precipitate. A minimum $\delta^{13} \mathrm{C}$-value of about $-30 \%$ was measured by the authors in such secondary phases by in situ SIMS analyses. The relatively low $\delta^{13} \mathrm{C}$-values measured in the GDZ of the Toarcian argillite next to the cement paste and concrete could illustrate a mixing between a pristine (mean $\delta^{13} \mathrm{C}$-value of $-1 \%$ ) and a cementitious carbonate (mean $\delta^{13} \mathrm{C}$-value of $-30 \%$ ) crystallized in high-pH conditions. Calculations indicate that the lowest $\delta^{13} \mathrm{C}$ composition of $-2.56 \%$ in the GDZ could result from dissolution of authigenic carbonates and crystallization of about $0.60 \mathrm{wt} . \%$ of cementitious carbonates. Such a minute carbonate re-precipitation is certainly insufficient for detection by classical mineralogical methods. This hypothesis of a combined 'dissolution-precipitation' process of carbonate species may result in the disappearance of authigenic dolomite and neoformation of new calcite and other Mg-rich phases. The changing $\mathrm{MgO}$ contents in the whole-rock, points to the redistribution of $\mathrm{Mg}$ in the GDZ with a clear Mg-enriched phase that precipitated at the external limit of the zone (Fig. 8). The mobility of this element was discussed by Fernandez et al. (2009b), a clear exchange between alkaline cations and $\mathrm{Mg}^{2+}$ from a compacted bentonite being observed during diffusion experiments. The newly-formed calcite carries a mean homogeneous $\delta^{18} O$ composition of about $26 \%$. This could correspond to an isotopic re-equilibration between the mineral and local fracture-water at a surface temperature of $12^{\circ} \mathrm{C}$, which is the mean temperature in the train tunnel. In support of this, a calcite in equilibrium with present-day fracture water $\left(\delta^{18} \mathrm{O}_{\text {fracture water }}=-8 \%\right.$ to $-7 \%$ ) (Patriarche, 2001) should be enriched by about $33 \%$ relative to water (fractionation parameter of Zheng, 1994) and provide $\delta^{18} \mathrm{O}$ values near $25-26 \%$. Combined with the carbonate dissolution-precipitation process, neoformation of a calcitic phase is evidenced in the GDZ. Part of this calcitic phase is poorly soluble as indicated by the leachates that are mainly depleted in $\mathrm{Ca}$ and $\mathrm{Sr}$ (Fig. 9); it may correspond to ettringite. This phase is known to occur in alkaline environments as a secondary mineral of low solubility (Perkins and Palmer, 1999). The soluble fraction or leachate, even if Ca-depleted (Fig. 9), is significantly enriched in radiogenic ${ }^{87} \mathrm{Sr}$ suggesting derivation of the element with a higher ${ }^{87} \mathrm{Sr} /{ }^{86} \mathrm{Sr}$ ratio from cement paste and/or concrete. As for the $\mathrm{C}$ isotopes, the ${ }^{87} \mathrm{Sr} /{ }^{86} \mathrm{Sr}$ increase in the argillite matrix can result from a mixing of a pristine Toarcian with a newly-formed cementitious soluble phase. To test this hypothesis, a mixing model has been computed (Fig. 11), according to the equations given by Faure (1986). The $\mathrm{Sr}$ contents and ${ }^{87} \mathrm{Sr} /{ }^{86} \mathrm{Sr}$ ratios that characterized the argillite pristine phase are, respectively, $500-550 \mu \mathrm{g} \mathrm{L}^{-1}$ and about 0.70779 . The cementitious soluble 

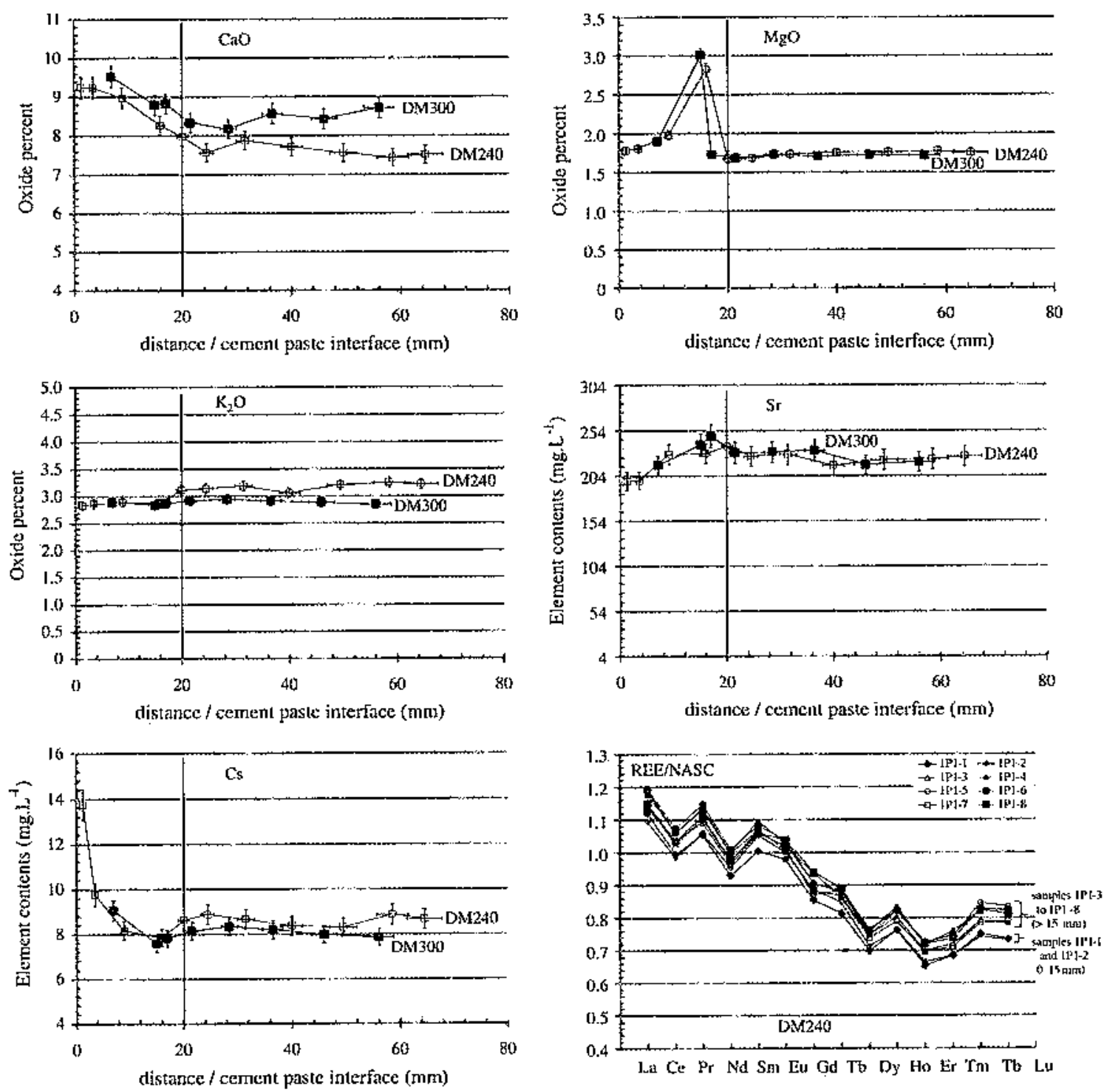

Fig. 9. Chemical composition for argillite whole-rosk in major, wace and pare-earth elements accorditrg to the distance to the tement piste interface at the DW240 and DM300 layers.

phase is more radiogenic $\left({ }^{87} \mathrm{Sr} /{ }^{86} \mathrm{Sr}=0.70835\right)$ with hercrogeneous Sr contents (from 230 to $400 \mu \mathrm{g} \mathrm{L}^{-1}$ ). Sample values from the DM180 $P 1$ profile define an intermediate domain between concrete and argillite end-menters, which is consistent with a proportion of 12-33 wt.\% of cementitious phases that have precipitated in the GOZ of the Toarcian afgilitie (33 wt.\% at the immediate contact and decreasing when moving away). The main part likely corresponds to $\mathrm{C}-\mathrm{S}-\mathrm{H}$ and/or portlandite phases and only $0.6 \%$ of these phases correspond to carbonates, as discussed above. Such high contents of secondary phases can expiain the clogging of the claysrone porosity (total porosity of the argillite decreasing from $9 \%$ in the reference samples to $1.9 \pm 0.3 \%$ in the 15-20 mm thick zone close to the concrete) (Gaboreau et al., submitted for publication). This imprint of cementitious fluids in the Toarcian arginte matrix appears to be recorded in more than $20 \mathrm{~mm}$ of argillite from the interface (Fig. 7a), which is more than the dark zone where. C-S-H were observed by mineralogical techaiques (10-15 mm). At the DM155 and DM180 layers, no stable feference state is reached in the last sample of the P1 profije
(20-25 mm), suggesting an imprint of cementitious fluids beyond this limit distance from concrete (Fig. 7). Unfortunately, no additional samples were available to constrain this hypothesis. When considering the trends of the ${ }^{87} \mathrm{Si} f^{665} \mathrm{Sr}$ data as a function of distance to the cement paste/concrete in the GDZ, linear functions can be fitted with correlation factors that range from 0.86 ro 0.96 (Fig. 7a). This refationship suggests a diffusion process for the propagation of the cementitious fluids into the argillite matrix. This propagation expands more greatly into the matrix of the deeper borehole layers than into that of the upper layers. When discontinuty surfaces are visible, for instance in the EDZ of the train tunnel, the fuid propagation appears to be less developed in the claystone matrix.

\subsubsection{In the micro-cracks ( $P 2$ scole)}

Along the few micto-cracks that developed perpendicularly to the cement paste/concrete interface ( $P 2$ profiles), no secondary minerals were unequivocally detected by the raked eye, even when suspected due to a bright crystalline aspect and a blue 

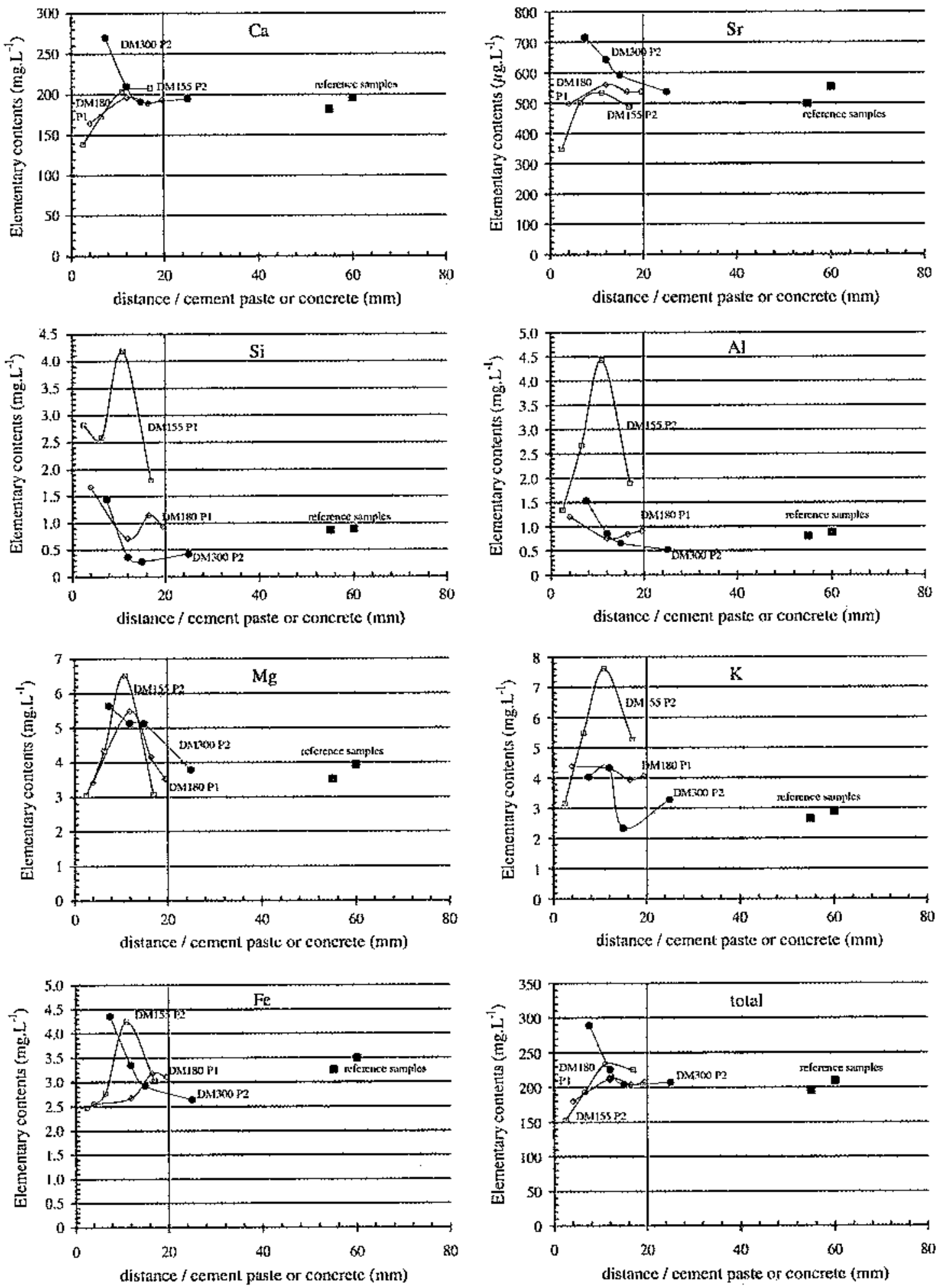

Fig. 9. Chemical composition for argiffte leachates away from and next to the cementitious materials from DM155, DM 180 and DM300 layers. Evolution along P1 (open symbols) and 12 profiles (black circles).

color. SEM and TEM observations clearly indicare mineralogical transformations, mainly with neoformation of ettringite, but also of caicite and $\mathrm{C}-\mathrm{S}-\mathrm{H}$ distributed in various rims over ca. $15 \mathrm{~mm}$. Measurement of carbonate contents reveals significantly higher values than those obtatned in the argilite matrix (P1 scale) at a similar distance from the cement paste/concrete interfice (Fig. 5b). The $C$ isotopic signatures of the carbonates, even if negative (which suggests an alkaline origin) are not as low as 


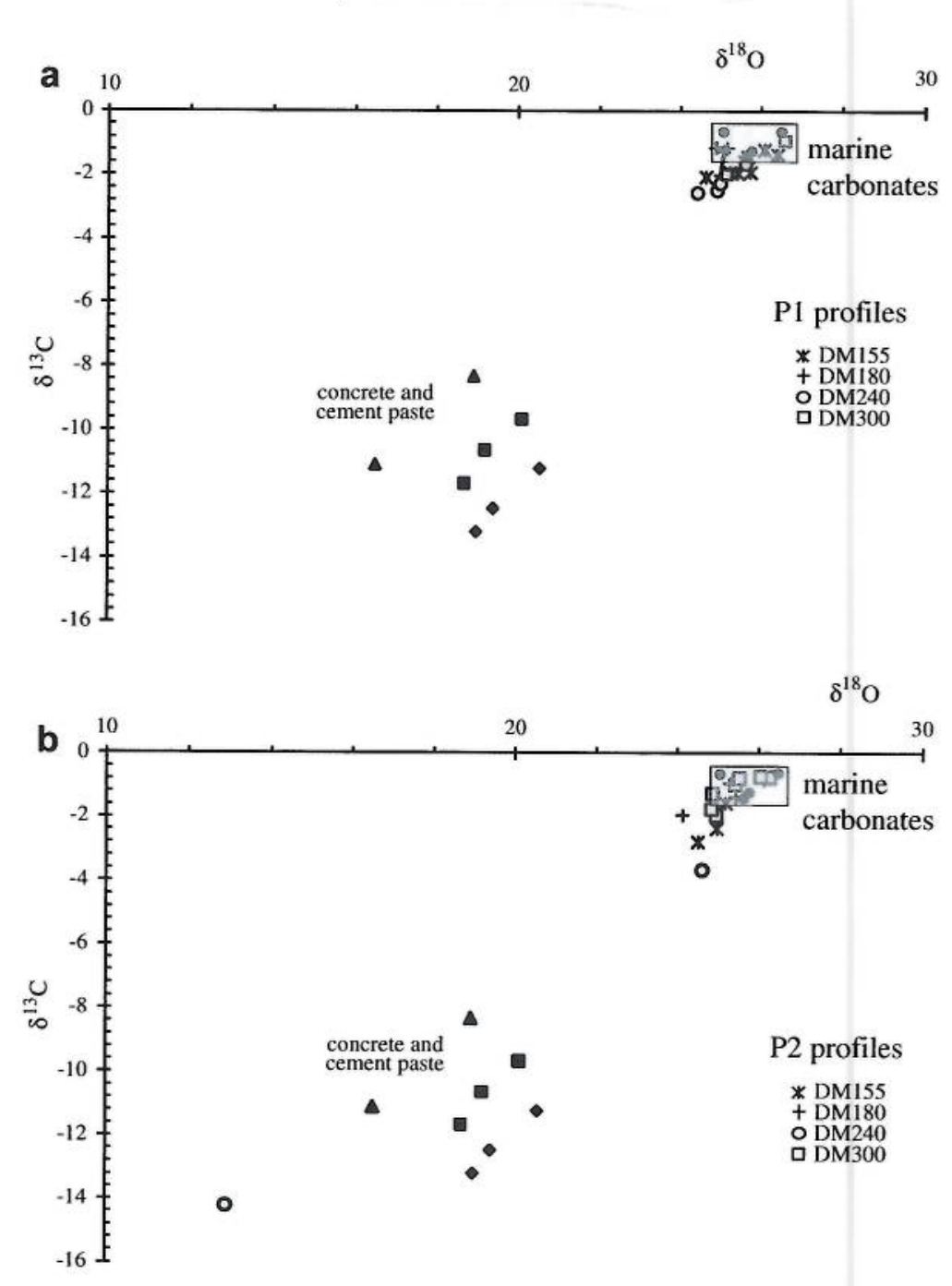

Fig. 10. $\delta^{13} \mathrm{C}$ versus $\delta^{18} \mathrm{O}$ diagram for the cementitious carbonates (cement paste and concrete), for the claystone carbonates and for carbonates extracted along the P1 and P2 profiles.

those expected for carbonates precipitating from alkaline fluids (Fourcade et al., 2007). This could result from a sampling artifact: the scraping could have removed some argillite matrix containing authigenic calcite. The P2 data thus reflect a mixing of secondary calcite precipitated on the P2 surfaces and marine calcite of the Toarcian matrix. Despite this potential artifact, it appears clearly that a P2 alteration superimposes that of the P1 matrix scale with lower $\delta^{13} \mathrm{C}$ values reported in the micro-cracks (Fig. 6a and b). Similarly, the chemical and isotopic $\mathrm{Sr}$ data obtained on the soluble fractions extracted from P2 material outline a trend of disturbance close to that obtained for P1 samples, but significantly higher. For instance, when considering the $\mathrm{Sr}$ mixing line (Fig. 11), the results obtained on the DM155 profile are located on the same mixing line as that obtained for the results from the $\mathrm{P} 1$ profile calling for mixing fractions of $45-100 \mathrm{wt} . \%$ of newly formed minerals through percolation of altering concrete fluids. Once again, the main part of these secondary phases likely corresponds to $\mathrm{C}-\mathrm{S}-\mathrm{H}$ and/or portlandite phases. A precise identification of the percolation process along the discontinuities (diffusion or any other mechanism) is challenging due to a possible sampling artifact (i.e., mixing between P1 and P2).

The two P2 profiles studied in the deep layers (DM240, DM300) also show specific behaviors. The micro-crack sampled at the
DM240 layer shows a very well expressed carbonation (20$32 \mathrm{wt} . \%$ of carbonate minerals), with low $\delta^{13} \mathrm{C}$ values ( $-3.68 \%$ to $-14.2 \%$ ) that are even lower than those of the cement paste. DM240 is the sole sample showing such high secondary calcite precipitation in the studied micro-cracks. In addition, the $O$ isotope composition $\left(\delta^{18} \mathrm{O}=12.6 \%\right.$ ) of these newly formed minerals is significantly abnormal when compared to that of the matrix or the other cementitious carbonates $\left(\delta^{18} \mathrm{O}\right.$ of about $26 \%$ ). The lower $\delta^{18} \mathrm{O}$ value in this layer is close to what is predicted for an equilibrium at higher temperature or in alkaline condition for $\mathrm{pH}$ higher than 10 (Fourcade et al., 2007). The low $\delta^{13} \mathrm{C}$ values are also compatible with precipitation from high-pH solutions. Therefore, it can be suggested that the changes observed in this layer of the DMborehole result from interactions that occurred in the first stage of the borehole infilling (soon after injection of the cement paste) and not from 15-a interaction.

Specific chemical and $\mathrm{Sr}$ isotopic data for the micro-crack sampled at the DM300 layer show: low ${ }^{87} \mathrm{Sr} /{ }^{86} \mathrm{Sr}$ ratios, high $\mathrm{Ca}$ and $\mathrm{Sr}$ contents, and high total elemental contents (Fig. 9). As a result, a single two end-member mixing cannot explain the patterns of the powders scraped from these micro-cracks (Fig. 11). In the Sr mixing diagram, the data define a range of compositions and contents that do not fit a mixing line, neither when considering the 


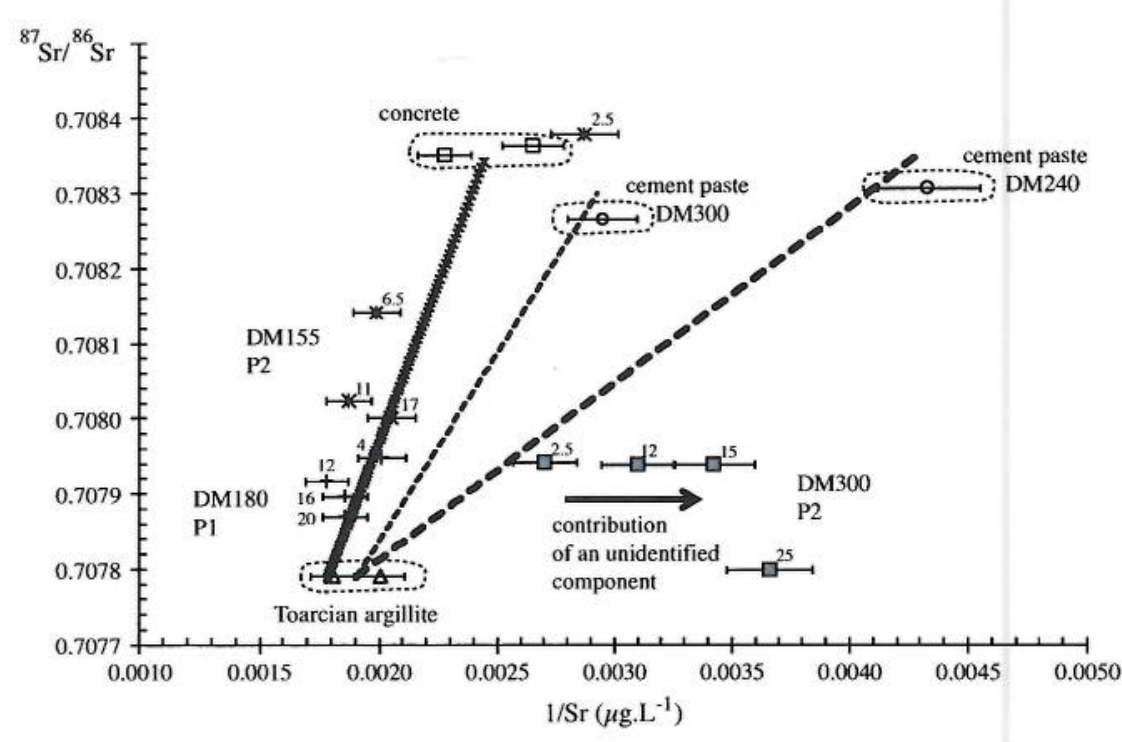

Fig. 11. Evolution of the $\mathrm{Sr}$ isotopic ratios $\left({ }^{87} \mathrm{Sr} /{ }^{86} \mathrm{Sr}\right)$ as a function of the $\mathrm{Sr}$ elementary contents $\left(1 / \mathrm{Sr}\right.$ in $\left.\mu \mathrm{g} \mathrm{L}{ }^{1}\right)$. Theoretical mixing between carbonates from Toarcian argillite and carbonates from cement paste or concrete are represented by the dotted lines connecting the two end-members (equation from Faure (1986)). Values measured in samples collected along three studied profiles (DM155 P2, DM180 P1, DM300 P2) are reported in this diagram with the reference of their sampling location (number above the symbols referring to the distance to the cement paste/concrete interface). The DM115 P2 and DM180 P1 data can be explained by a two-end member mixing as defined above. Values reported along the DM300 P2 profile cannot be interpreted as a consequence of cementitious material/argillite interaction (see text for explanations).

characteristics of the cement paste, nor when considering those of the concrete (Fig. 11). It can be predicted that the percolation of high-alkaline fluids is not the only process responsible for the crystallization of secondary minerals observed in the micro-cracks of the deep layer of the DM borehole. In the hypothesis of a mixing model, the data call for a third mixing component that could have had a greater imprint than the alkaline one and may be in equilibrium with the Tournemire present-day fracture water, if considering the $\delta^{18} \mathrm{O}$ patterns. The imprint of this unidentified component is especially important, as the sample is located far from the interface with the cement paste, and, therefore, next to the over-coring pipe. Such data could call for a contamination process with a solution depleted in $\mathrm{Sr}$ at surface temperature, for instance with water pumped into the Tournemire canal during the over-drilling. This water corresponding to that of the Cernon fault could have stayed in the depth of the borehole and impacted the external samples.

\subsection{The isotopes as tools for tracking imprints of high-pH fluids}

The combination of $\mathrm{C}$ and $\mathrm{Sr}$ isotopes allows discrimination between carbonates and other soluble phases that are the main markers of high-alkaline fluid percolations in a clay-rich medium. This isotopic approach appears, therefore, very appropriate for tracking the occurrence of very discrete percolations of high-alkaline fluids, to evaluate their interactions with the natural host rocks, to discuss their spatial extents and to demonstrate their origin. The use of isotopic markers is extremely important in contexts where mineralogical changes are tiny and not sufficient enough to be detected directly by means of routine methods. For instance, $\delta^{3} \mathrm{C}$ and $\delta^{18} \mathrm{O}$ data allow distinction and identification of newly-formed cementitious carbonates. These carbonates can be calcite, hydrotalcite or thaumasite in the context studied here. Discrimination between these various types of minerals is difficult but can be evaluated by considering the chemical compositions of the whole rocks. For instance, in the matrix scale (P1 scale) of the external zone of the $\mathrm{GDZ}$, an increase in $\mathrm{MgO}$ and $\mathrm{Al}_{2} \mathrm{O}_{3}$ contents suggests the precipitation of hydrotalcite. The $\mathrm{Sr}$ isotope data also give complementary information on other soluble phases and in their proportions, as for $\mathrm{C}-\mathrm{S}-\mathrm{H}$. As a result, combined $\mathrm{C} / \mathrm{O}$ and $\mathrm{Sr}$ isotopic data clearly identify an alkaline fluid imprint. This imprint appears to be more extended when considering isotopic patterns than on the basis of the sole mineralogical results, which reflects the difference in sensitivity of the two tracers. Alternatively, isotopic methods are much more sensitive and extremely tenuous variations in mineral content can induce significant changes in the signal. On the basis of $\mathrm{C}$ isotope measurements, it is possible to detect for instance the neoformation of less than $1 \%$ of very low- $\delta{ }^{13} \mathrm{C}$ cementitious carbonate in samples of marine origin. Furthermore, using XRD or SEM to detect and identify cementitious phases such as $\mathrm{C}-\mathrm{S}-\mathrm{H}$, is often challenging in low intensity processes, but this can be improved with combined isotopic approaches. Variations between the $\mathrm{GDZ}$ and the mineralogical altered zone can thus be viewed as a difference in the detection limits of the analytical methods used.

Although the sensitivity of the Cand $\mathrm{Sr}$ isotopic methods is clearly well-suited for tracking most of the minerals formed during high-pH fluids interactions in the studied DM-borehole, it should be noted that ettringite and/or C-A-S-H can also form (Gaucher and Blanc, 2006; Fernandez et al., 2009a; Dauzères et al., 2010a). There are still uncertainties about the solubility of these minerals (Myneni et al., 1998; Perkins and Palmer, 1999), but they appear to be more stable in acetic acid leaching conditions, and are probably not extractable by the HAc protocol used in this study. A selective extraction method for the more stable mineral phases needs to be promoted to improve the evaluation of the imprint of the alkaline fluids into clay-rich media.

Last but not least, the isotopes offer the opportunity to define the origin of fluids. In the case of the DM borehole, the observed mineralogical transformations were initially attributed to high$\mathrm{pH}$ fluid percolations. Importantly, changes defined along the discontinuities in the deepest layer of the core cannot be explained by a single cement/argillite interaction, and thus cannot be considered as an appropriate analogue for studies on interactions among clay/cement paste or concrete. 


\section{Conclasions}

The interactions between natural clay and cementitious materials were assessed in a 15-a old engineered antalogte for deep geological storage, using a combined mineralogical and chemical isotopic study. This exceptionat analogue was observed in the IRSN Tournentite experimental tunnel in Aveyron, France, along a $3 \mathrm{~m}$ long borehole (DM borehole). To assess the behavior of the Toarcian argillite that was in direct contact with a CEM li cement paste or a CEM 11 concrece for 15 a the variarions of the argillite wholerocks were tracked as well as of selecrive extracted mineral phases. The whole rock $\mathrm{CO}_{2}$ extraction and $\mathrm{O} / \mathrm{C}$ andlysis were aimed at tracking the occurrence of cementitious carbonates, whereas feachates obtained by dilute acid reactions at a low acid/rock ratio consisted mosrly of soluble mineral phases stuch as carbonates, $C$ S-H and portandire.

The study also emphasizes how the isotopic variations mimic the mineralogical changes with a somewhat extended volume of alteration. The thickness of disturbance and the relative proportion of newly-formed minerals can be estimated in the argillite matrix and in the secondary micro-cracks; the origin of the fluids responsible for their crystallization was also identified. By this combined mineralogical and chemical/isotopic approach, the role of cementitious materials can be better evaluated and validated in engineered analogues. Furthermore, the presence of cementitious secondary minerals and their relative contents could be tracked in the 'geochemical tisturbed zones' (GDZ) over greater distances by these isotope methods, than by the classical mineralogical techniques. This difference emphasizes the potential of isotopes as appropriate tools for the characterization of alteration processes among cement naterials and natural clays after long-lasting interactions. Quantitative and predictive modeling may now be determining ir: the interpretation of the described disturbances.

The study also outlines the scale and the cype of tisturbances that may occur in claystones when interacting with cemene paste or concrete, which is expected in a deep disposal storage. After 15 a of interaction, the observed changes are extremely limited in the clay-rich matrix as the alteration extends over a few centimeters, thus resulting from slow and discrete processes. The changes are of the same order of magnitude in micro-cracks induced for instance in an EDZ.

The data indicate that disturbances in a deep storage wil] mainly affect the near field and will not extend into the geological barrier. Aternatively, they could contribute to the insulation of the waste package as they are mainly characterized by the neoformation of amorphous phases $(\mathrm{C}-\mathrm{S}-\mathrm{H})$ and to a lesser extent of calcite, intimately linked to the clay matrix and to a clogging of the rock porosity.

\section{Acknowiedgenents}

The authors would like to thank the CNRS apd IRSN for funding this project in the frame of the CNR TRASSE (Research Action Nunber 2008-2B) corresponding to the GNR TRASSE Contribution Number $2011-07$. The authors would also like to thank the reviewers fot their very constructive comments on a previous draft of this publication.

\section{References}

Aderot. F., buit, M. 1992. Modelling of the corrosion of cement paste by de-ionized water Cem Concr. Mes $22,480-496$.

Alkins, M., Classer, F.P., Motonj, L.P., 199 . The leng term properties of cement and concretes, Mater. Res, 50, Symp. Pfoc, $212,373-38 f$,

Atkinson, A, Hamis, A.W., Hearnc, 1 A., 1985. Hydrothermal Alterstion and Ageiltg of

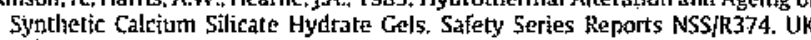
Nirex Eimiled, Harwell bK.
Berner, U.R. 1992. Evolution of pore waler chemistry during degradation of ccment in a radionctive waste repository environment. Waste Manage, $12,201-219$.

Boisson, I.Y., Bertiand, $L$ heitz, J.F., Noreat-Ze Golvan, $Y_{,}$2001. In situ and Iaboratory investigations of lluix flow through an arziflaceous formation at different scales of space and lime. Toumemire tunnet, southern fiance. Hyilogeol. J. 9, 108-123.

Chauer, N., Chatulhuri, S. 1995. Clays in Crustal Environments. Isotope Dating and Tracing. Springer Veritzg. Heidslberg Berlin, New York

Dauzeres, A, Le bescop. P., Sardini, [2., 2009. Physico-chemical investigation of cement baste degractation in a clayey envienment: experimental approach and preliminary modelfing. In: Concrete in Agpressive Aqueous tinvironment, Performance. Testing and Modelling, 3-5 june 2009. Toulouse, France, BulEM Proc. PRO 63, 1, Pp. 228-239.

Dauzeres, $A$, Le leseop, R., Sirrdini, P., Cau Dit Coumes, C., 2010z. Pliysico-chemical investigation of clayey/cement-based materials interaction in the context of geological wasle disposaz, experimental approach and results. Cem, Concr. Res. $40,1327-1340$

Dauzèves, A. Le Bescop, P. Sordint, P. Cau Dit Coumes, C. 2010b. Study of CEM I and tow pH cement paste leaching in multi-ionic underground water. En: Concrete Under Severe Conditions-envirennient ant laading, CONSEC f0, Meriala (Mexique) 1. pp. 495-503.

De Windt, L Pellegrini, D., Van Der Lee, J., 2004. Coupled mothelling of cement claystane intercactions and radionuclide migratian. Contam. Hydral. 68, 165I 82 .

De Windt, $L_{4}$ Marsal, F., Finscau, E, Pellegrini, D., 2008. Reactive transport modeling

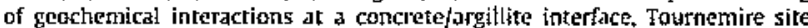
(France). Phys. Chem. Earth 33, 295-305.

Elie, M. Techer, L. Trotignon, 1, Khoury. ft Salameh, E Vandarane, D, Boulvais, P. Fouterde, S., 2007. Cementation of kerogen-rich marls by alkatine fluids rejensed during weathering of thermally metamorphosed marly sediments. Pagr Il: Organic matter evolution, magnetic susceptibtticy and metals (Ti. Gr. Fe) at the Khusthiym Matruk natural analogute (Central Jorlan). Appl. Geothem. 22, $131 i-1328$.

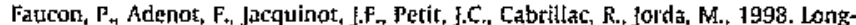
term behwiour of centent pastes used fot nuclear waste disposat: review of physic-chemical nechanisms of water degradation. Cem. Concr. Res. 28, 847857.

Faure, G. 1986. Ptinciples of Isotope Geology. secand ed. John Wilcy \& Sons.

liernandez, $R_{+}$Cuewas, $J_{+}$Mader, $\mathrm{U}_{4}, 2009 \mathrm{z}$, Modelling concrete interaction with a bcetopite barrier, Eug, 1 . Minerat. 21, 177-191.

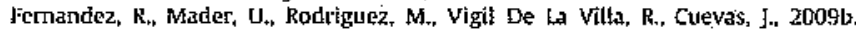
Alteration of compacted bentonite by diftusion of highly alkaline solutions. Eur. J. Mineral 21, 725-735.

fourcade, S, Techer, I., Boulwais, P., Elic, M., Trotignon, L. Vandanms, D., 2007. Cementation of a clayey sedinent by allialine fujids released by combustionproduced cements: l. Lsotople $(\mathrm{C}, \mathrm{O})$ art palemagnetic study of the Klushłayn Matruk naturał analogue (Central Jerklan). Appl. Geocluem. 22. $1293-1310$.

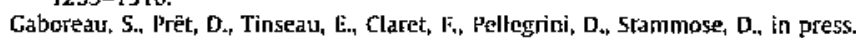
15 Years of in situ cemient-argillite interaction foon Tournemire UR: charncterisation of the multi-scale spatial heterogencities of pore space evolution. Appl. Geochetn. doi:10.1016/s.apgeochem.201 1.07.013.

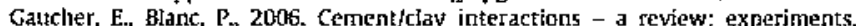
natural analogues, and modelity. Waste Manage. 26, 776-788.

Hewletr. P.C., 1998. Leas's Chemistry or Cement and Concrete, fourth ed. Lisevier, Butterworth-Heinemant.

Iden, I.K. Hagetï, P., 2003. C, 0 and $S$ isotopic signatures in concrgte which have suffered thuumasire forniation and limited thaumasite form of sulfate altack. Cem, Concr. Compos, 25, 839-846.

Khoury, H., Salameh, $E_{4+}$ Abdut -Jaber, Q. 7985. Characteristics of an unusual highly alkaline water frors the Maqarin arca, Northerr Jordan. J. Hydrol. 81. 79-91.

Le Bestop. P.. Solet. C. 2006. External Sulplate Attack by Ground Water. Revue Europtétne de Gétrie Civil.

Letolle, R, Gegont, P', Moranville-Regourd, M., 1992, Strble isotopes of carben and oxygen for the study of carbonation/decarbonation processes in concretes. Cem. Concr. Res. $22(2-3), 235-240$.

Linktater, C.M., Albinsson, Y., Alexander, W.R., Casa, L., McKïnlay, t.G., Sellin, P., 1996. A natural anatogue of high-pH cenent pore waters from the Maqarith area of northarn Jordan: comparison of predicted and obserwed trace-element clumistry of uranium and selenitum. ]. Contan. Hydrel. 21, 59-69.

MeCrea, J.M., 1950. On the isotope chemistry of carbolutes ind a paleotemperattire scale. f. Chem. Phys. 18, 849-857.

Micttel, 0., 1999. Caractérisation isolopique Rb/Sr et Pb/Pb des roches totales, fles minéraux de remplissage de fracture et des eaux des formations sédimentaires jutassiques de Tourthemire (Aveyron. France). Implications sur les interactions Eau/Roche passtes el actuelles. Thëse de doctorat de l'Université de Montpolliẹ 11.

Mllodowski, A.E. Hyslop, F.K.. Khouny, H., Hugues, C., Mader. UK.. Griltault, L. Trotignon, L, 2001. Mineralogical alteration by hyper-alkaline gtoundwaters in morthern Jordan. [n: Cidu, R. (Ed.). Proc. foth Internat. Symp. Water-Rock tnteraction - WR! 10, Balkenła, pj?. 1347-1350.

Myneni. S.C.B., Traina, S.t., Logan, T.j.. 1998. Ettringite solubility and geochemistry of the $\left.\mathrm{Ca}(\mathrm{OH})_{2}-\mathrm{Al}_{2} \mathrm{SO}_{4}\right)_{-1} \mathrm{O}$ system at 1 atm pressure and $298 \mathrm{~K}$, Chem, Geol. 148, 1-19.

Patriarche, D. 2001, Caractérisation ct modélisation des transterts de traceurs maturels dans les argilites de Tournemire. Thèse de doctorat Hydrologie et 
Lytrogéologie quanlitatives, CIG - Centre d'Informatiqute Gệtogique, l'aristcch. ENSMP.

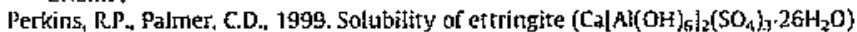
at 75 ' $\mathrm{C}$. Geothim. Cosmochim, Acta 63. 1969-1980.

Pín, $C_{+}$Joannon, S., Bosq. C., Le Fèuse, B., Gautlier, P.J., 2003. ['recise determination of th, Sr, Ba and $\mathrm{Pb}$ in geological materials by isotope dilution and ICPquadrupole mass spectrometry following selective sepatation of the anabres. J. $_{\text {. }}$ Anal. At Spectrom. 18, 135-141.

Plancl, D., Sercombe, I., Le Bescop, F. Adenat, F. Torrenti, f.Mf, 2006, Long-term performance of cenicht paste during combined calcium leaching-sulfate attack: joinetics and size effect. Cem. Concr. Ras. 36. 137-143.

Rarnirez, S.R. Cuevas, J. Vigil, R., Leguey. 5., 2002. Hydothermal alteration of "La Serrata" bentonile (Attouti $257-269$.

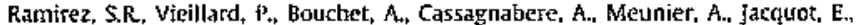
2005, Atteration of the Callowo-Oxfordian clay from Meuse-Hature-Marne

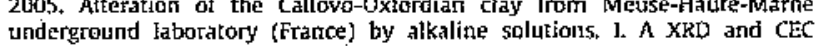
study. Appl. Georhem. 20, 89-99.

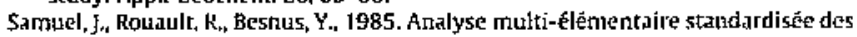
materiaux géologiques en specrométrie d'émissian par plasma à couplage inductif. Analysis 13, 312-317.
Savagc. D. Noy, D., Mhara, M., 2002. Modelling the inleration of bentonile with hyperalkaline fluids. Appl. Geochem. 17, 207-223.

Tayior, El.F.W. 1997. Cement Chemistry, Academic Press, London, UK.

'Iecher, t., Khoury, H.N., Rassinewx, F., Salamelt, E., Claude, C., Clatere, N., Pagel, M., Lancelot, J., Griftatult, L., Jaçuot. E.. 2006. Propagation of alkaline fluids in an argiltaceous forthation: study of the Khushaym Matruk natural analegue (Central Jordany. J. Geochem. Explor. 90. 53-67.

Techer, I. Clauer. N.. Liewig. N.. 2009. Ageing effect on the minetal and chemical composition of Opalinus Clays (Mont Terti, Switzerland) after excavation atid surface storage. Appl. Cenctem. 24, 2000-2014.

Tirtsedu. E., Battet. D. Hassouta. Lo Dewol-Erown I., stammose, D. 2006 Minerabgical clatratterizalion of the Toutnemire algillite after in situ interaction wilh concretes. Waste Manage. 26, 789-800.

Van der lese, $Y$, 1998. Thernodyuamic and Marhematical Concepts of CAlEss. Techntcal keport Nr LHW/RD/98/39. Ecole des Mines de Paris, Fontainebleau,

France.
Vicillard, P., Rassineux, F., 1992. Thermodynamic and geochemical modeling of the alteratien of two eertent matrices. Appl. Geochem. 7 (Stpp. 1), 125-136.

Zheng, Y.F. 1994. Oxygen isotope Fractionalfon in metat monoxides. Mitterat. Mag $58 A, \pm 000-1001$. 